\title{
Y705 and S727 are required for mitochondrial import and transcriptional activities of STAT3 and regulate proliferation of embryonic and tissue stem cells.
}

Margherita Peron ${ }^{1^{*}}$, Giacomo Meneghetti ${ }^{1^{*}}$, Alberto Dinarello ${ }^{1^{*}}$, Laura Martorano ${ }^{1}$, Riccardo M. Betto ${ }^{2}$, Nicola Facchinello ${ }^{1}$, Annachiara Tesoriere ${ }^{1}$, Natascia Tiso ${ }^{1}$, Graziano Martello ${ }^{1 \wedge}$, Francesco Argenton ${ }^{1 \wedge}$.

${ }^{1}$ Department of Biology, University of Padova, Padova, Italy,

${ }^{2}$ Department of Molecular Medicine, University of Padova, Padova, Italy.

* The authors contributed equally to this work.

$\wedge$ Co-corresponding authors

\section{ABSTRACT}

The STAT3 transcription factor, acting both in the nucleus and mitochondria, maintains embryonic stem cell pluripotency and promotes their proliferation. In this work, using zebrafish, we determined in vivo that mitochondrial STAT3 regulates mtDNA transcription in embryonic and larval stem cell niches and that this activity affects their proliferation rates. As a result, we demonstrated that STAT3 import inside mitochondria requires Y705 phosphorylation by Jak2, while its mitochondrial transcriptional activity, as well as its effect on proliferation, depends on the MAPK target S727. These data were confirmed using mouse embryonic stem cells: Y705 mutated STAT3 cannot enter the mitochondrion while the S727 mutation does not affect mitochondrial import of the protein. Surprisingly, STAT3dependent increase of mitochondrial transcription seems independent from STAT3 binding to STAT3 responsive elements. Finally, loss of function experiments, with chemical inhibition of JAK/STAT3 pathway or genetic ablation of stat3 gene, demonstrated that STAT3 is also required for cell proliferation in the intestine of zebrafish. 


\section{INTRODUCTION}

The investigation of the role of Signal Transducer and Activator of Transcription 3 (STAT3) pathway in human diseases represents, to date, one of the most exciting developments in modern medicine (O'Shea et al., 2015). Many of the major human malignancies display elevated levels of constitutively activated STAT3 (Johnston and Grandis, 2011). Most interestingly, recent data report that STAT3 target genes are overexpressed in tumourinitiating cancer stem cells (Fouse and Costello, 2013; Wei et al., 2014; Ghoshal et al., 2016). Stat3 is also the key mediator of Leukemia Inhibitory Factor (LIF) in mouse embryonic stem cells (ESCs) where the LIF/STAT3 axis promotes the maintenance and induction of naïve pluripotency (Burdon et al., 1999; Matsuda et al., 1999; Smith et al., 1988; Martello et al., 2013).

STAT3 transcriptional activity is regulated by phosphorylation of two separate residues. When Janus kinases 1/2/3 (JAK1/2/3) phosphorylate its tyrosine 705 (Y705), STAT3 dimerizes, enters the nucleus, binds to STAT3 response elements and triggers transcription of its target genes ( $\mathrm{Ni}$ et al., 2004). On the other hand, the function of serine 727 (S727) phosphorylation remains controversial; pS727 has been reported to have both activating and inhibitory effects on STAT3 transcriptional activity (Quin et al., 2008; Shi et al., 2006). More recently, it has been demonstrated that pY705 is absolutely required for STAT3-mediated ESCs self-renewal, while pS727 is dispensable, serving only to promote proliferation and optimal pluripotency (Huang et al., 2014). Notably, zebrafish mutants lacking maternal and zygotic Stat3 expression display transient axis elongation defects due to reduced cell proliferation during embryogenesis (Liu et al., 2017). Additionally, it has been demonstrated that in zebrafish Stat3 is transcriptionally active in stem cells of highly proliferative tissues like Tectum Opticum ( $\mathrm{TeO}$ ), hematopoietic tissue and intestine (Peron et al., 2020).

Besides its canonical nuclear functions, a pool of STAT3 has been reported also in the mitochondrion of different cell types, thus including this transcription factor in the large family of dual-targeted proteins with both nuclear and mitochondrial functions (Wegrzyn et al., 2009; Mantel et al., 2012). A recently discovered subcellular localization of STAT3 is the Endoplasmic Reticulum (ER), where it controls the release of $\mathrm{Ca}^{2+}$, with consequences on the mitochondrial $\mathrm{Ca}^{2+}$ levels and on the life-death cell decision. This function is crucial for the maintenance in the tumour niche of apoptosis-resistant cells (Avalle et al., 2019). 
Although the mechanisms of action of mitochondrial STAT3 (mitoSTAT3) are still debated, between 10 and $25 \%$ of total STAT3 has been shown to be in the mitochondria, (Szczepanek et al., 2011; Carbognin et al., 2016). Using different in vitro models, several roles have been proposed for mitoSTAT3, such as: interaction with mitochondrial respiratory chain complexes I and II; binding to the d-loop regulatory region of mitochondrial DNA (mtDNA); regulation of mitochondrial gene expression; regulation of mitochondrial permeability transition pore (Wegrzyn et al., 2009; Macias et al., 2014; Meier and Larner, 2014; Carbognin et al., 2016). However, the molecular mechanisms leading to mitoSTAT3 activation and translocation are still only partially understood. Previous in vitro studies suggested that the S727 phosphorylation by MAPK kinases may be required for STAT3 mitochondrial activity (Gough et al., 2013) and it seems necessary to restore complexes I and II activities in Stat3 ${ }^{/-}$cells (Wegrzin et al., 2009). Moreover, pS727 STAT3 targeted to the mitochondria is described to promote Ras-dependent transformation in human bladder carcinoma cells (Gough et al., 2009). Notably, the role of other post-translational modifications on mitoSTAT3 activity have not been investigated yet.

Mostly due to its transparent body and external fertilization, Zebrafish is an organism widely used for analysis of gene expression and protein-gene functions. Knowing that the STAT3 protein and all its functional domains are highly conserved in zebrafish (Liang et al., 2012, Oates et al., 1999) we used this animal model to study the mitoSTAT3 pathway in vivo. In this paper we demonstrate the dependence of mitoSTAT3 activities from both Y705 and S727 phosphorylation, hence, that mitoSTAT3 mitochondrial function relies on both ERK and JAK1/2/3 kinases activation. Our data also show that mitoSTAT3 modulation of mitochondrial transcription does not require STAT3 DNA binding domain, consistently with the differences between the eukaryotic and the prokaryotic transcriptional machineries operating in the nucleus and mitochondria, respectively. Finally, using zebrafish larvae, we directly linked the STAT3-dependent regulation of tissue stem cells proliferation to mitochondrial transcriptional activity. 


\section{RESULTS}

\section{mitoSTAT3 regulates cell proliferation in the PML of the TeO through mtDNA}

\section{transcription}

It is known that in keratinocytes and mouse ESCs a portion of STAT3 localizes to mitochondria, where it induces mitochondrial transcription and cell proliferation (Macias et al., 2014; Carbognin et al., 2016). Hence, we tested whether STAT3 and mitochondrial transcribed genes colocalize in proliferating regions of the zebrafish embryo, considering this colocalization a "conditio sine qua non" in a STAT3-mitochondrial-proliferation liaison. Facilitated by the fact that $m t$ nd2 expression profile has already been described in zebrafish (Thisse et al., 2001) and considering the polycistronic nature of mtDNAtranscribed genes, that results in stoichiometric mtDNA transcription (Taanman, 1999), we decided to use this mitochondrial gene as a hallmark of global mitochondrial gene expression. As described in Fig 1, mt_nd2 and the cellular proliferation marker pcna are particularly expressed in regions also labelled by Stat3 transcripts, such as the inner retina and the Peripheral Midbrain Layer (PML) of the Tectum Opticum (TeO) (Fig. 1; Fig. 2A), the progenitor source for tectal and torus neurons in the embryo (Galant et al., 2016).

In order to understand whether STAT3 mitochondrial activity regulates mtDNA transcription and promotes proliferation also in vivo, we injected zebrafish fertilized eggs with mRNA of a mitochondria-targeted murine form of Stat3 (mStat3), provided with a nuclear export domain that makes it unable to localize to the nucleus (MLS_mStat3_NES) (Fig. S1 A). This chimeric protein a) is completely devoid of nuclear functions as assessed by qRT-PCR analysis of Socs3, the most direct Stat3 target gene (Fig. S1 B) and b) efficiently localizes only inside the mitochondrion as revealed by its co-localization with the mitochondrial marker ATAD3, both in transfected mouse ESCs, and in zebrafish cells (Fig. S1 C; Fig. S2 A,B).

When MLS_mStat3_NES mRNA was injected into zebrafish embryos we could observe that this modified form of Stat3 was unable to induce the expression of its target gene socs3a (Fig. S3 A), however, we detect, both by in situ hybridization and qRT-PCR, a significant increase of mitochondrial transcription at 24 and 48 hours post fertilization (hpf) (Fig. 2A-A', C; Fig. S3 B-D). It is worth noting that, as assayed by pcna analysis, overexpression of MLS_mStat3_NES mRNA also induced a proportional increase of proliferating cells in the same tissues where mitochondrial transcription was stimulated, i.e. 
the PML (Fig. 2 B-B', C, D). On the other hand, we did not find any difference in mtDNA content when comparing injected and control embryos, suggesting that the effect of mitoSTAT3 on mitochondrial transcription is not due to increased mtDNA replication or mitochondrial biogenesis (Fig. 2E).

Importantly, chemical inhibition of mitochondrial transcription by using Balapiravir (Feng et al., 2015) was able to abolish MLS_Stat3_NES effects on proliferation (Fig 2 A", B', D), thus providing evidence, in vivo, that replication of highly proliferating PML cells in the developing $\mathrm{TeO}$ of zebrafish embryos depends on mitoSTAT3-driven expression of mitochondrial genes.

\section{Mitochondrial STAT3 transcriptional activity relies on phosphorylation of both S727 and Y705.}

Additionally, we wanted to dissect the domains of STAT3 that are needed for the activation of mtDNA transcription, hence focussing our experiments on the DNA binding and the activation domain.

Putative STAT3 binding elements (SBE) have been identified in the mitochondrial D-Loop (the mitochondrial transcriptional initiation site) (Macias et al., 2014) and STAT3 was found to immuno-precipitate together with the mitochondrial D-Loop in mouse ESCs (Carbognin et al., 2016). Nonetheless, a form of mitochondrial STAT3 mutated in the DNA binding domain (STAT3 458-466 VVV-AAA) (MLS_mStat3_ADNAbd_NES), thus unable to bind SBE (Horvath et al., 1995), retained its ability to activate mt_nd2 transcription at comparable levels with respect to wild type (WT) mitoSTAT3 on zebrafish embryos (Fig. 3 $\left.A, A^{\prime}\right)$. It is worth noting that this DNA binding mutant form when transfected in mouse ESCs is still able to co-localize with ATAD3, a mitochondrial nucleoid marker, (Fig. 3 B). This result suggests that binding of STAT3 to its specific response elements is dispensable for mtDNA transcription.

The nuclear activity of the STAT3 activation domain is known to be controlled by JAK1/2/3mediated phosphorylation on Y705 residue, which also ensures STAT3 monomers stability in the cytoplasm (Becker et al., 1998). On the other hand, phosphorylation on STAT3 S727 by the MAPK pathway (Ras-Raf-MEK-ERK pathway) is known, from in vitro studies, to enhance the Electron Transport Chain (ETC) (Wegrzyn et al., 2009) as well as to promote cell proliferation and optimal pluripotency (Huang et al., 2014). To verify in vivo the post-translational requirements, and to test whether also mitoSTAT3 activity requires 
Y705 phosphorylation, we decided to inject 1-cell stage zebrafish embryos with mRNAs encoding variants of murine Stat3. Specifically, we compared the activity of WT STAT3 (without the MLS) with two mutated forms, Y705F and S727A, able to prevent phosphorylation of residues 705 and 727, respectively (Mohr et al., 2013; Huang et al., 2014). Interestingly, when embryos were injected with the WT isoform, quantitative analysis of fluorescent in situ hybridization revealed a significant increase of mitochondrial transcription in the PML of the TeO (Fig. $4 \quad$ A,B). qRT-PCR analysis on homogenized embryos detected an increase of global $m t \_n d 2$ gene expression (Fig. $4 \quad$ C,D), which failed to reach statistical significance. Notably, when injecting either Y705F or S727A isoforms of STAT3, no stimulation of mitochondrial transcription in the PML population was detected, either using in situ hybridization or qRT-PCR (Fig. 4 A-D; Fig. S4 A). In conclusion, both phosphorylations are needed for STAT3-mediated increase of mtDNA transcription in the PML. On the other hand, when the mutated isoforms are forcedly targeted only to the mitochondrion (by using both the MLS and the NES), the S727A mutation prevented mitoSTAT3-mediated activation of $m t$ nd2 gene expression, while the STAT3-Y705F mutated isoform retained its mitochondrial transcriptional activity (Fig. 4 E,F; Fig. S4 B). This implies that Y705 is not directly involved in mitochondrial transcription.

Given that STAT3 Y705F had no direct effect on mitochondrial transcription (Fig. 4), we hypothesised that the tyrosine 705 could regulate STAT3 localization. To further elucidate the localization of mutated STAT3, we performed immunofluorescence analysis on mouse Stat3 $^{-/}$ESCs transiently transfected. While transient transfection of STAT3-Y705F resulted in its nuclear and sporadic mitochondrial localization, transfected mitoSTAT3-Y705F localised exclusively to mitochondria (Fig. 5 A). Surprisingly, upon isolation of mitochondrial fractions followed by western blot analysis we could detect STAT3-Y705F, as well as WT STAT3, in mitochondria (Fig. 5 B-C). Nonetheless, transmission electron microscopy (TEM) analysis after DAB (3,3'-Diaminobenzidine) immunohistochemistry revealed that, while WT STAT3 and MLS_STAT3_NES localize inside mitochondria, staining cristae of the inner mitochondrial membrane (Fig. 5 D), STAT3 Y705F forms clots along the edges of mitochondria and displays a diffuse cytoplasmic signal, fails to migrate through the outer mitochondrial membrane and intermembrane space, thus confirming that Y705 is essential for the correct localization of STAT3 inside the mitochondrion.

\section{STAT3 S727 phosphorylation is needed for mitoSTAT3-driven promotion of cell}




\section{proliferation in the PML}

As phosphorylation to STAT3 S727 is needed for mitoSTAT3-driven mtDNA transcription, we tested whether this post-transcriptional modification is also required for the increase of PML proliferation downstream of mitochondrial RNA production in the PML.

Indeed, the proliferation rate in the PML of 48-hpf embryos injected with MLS_mStat3_NES_S727A mRNA resulted significantly lower to that of embryos injected with WT MLS_mStat3_NES mRNA (Fig. $6 \mathrm{~A}$ ), indicating that $S 727$ phosphorylation is crucial for proliferation in the PML. Moreover, we performed immunofluorescence and western blot analysis on Stat3-/- mouse ESCs transiently expressing either WT STAT3, STAT3 S727A, or MLS_STAT3_NES, showing that mitochondrial localization of STAT3 is not affected by the S727A mutation (Fig. 6 B,C).

On the other hand, it is known that in mouse 3T3 fibroblasts the MEK-ERK pathway is responsible for phosphorylation of STAT3 S727 (Gough et al., 2013). In order to evaluate in vivo the involvement of MAPK pathway in phosphorylation of $S 727$, and its downstream effects for mitoSTAT3-driven cell proliferation, we decided to use the MEK kinases inhibitor PD98059 (Alessi et al.,1995), commonly used in vitro to prevent S727 phosphorylation (Tian and Al., 2004; Wang et al., 2019). First, we tested this compound in 3T3 mouse fibroblasts checking the levels of STAT3 pS727 by western blot. Once confirmed that PD98059 downregulates the phosphorylation of S727 in 3T3 cells (Fig. S5 A), we administered this compound to zebrafish embryos. Interestingly, WT larvae treated from 24-48 hpf with PD98059 displayed a significant reduction of $m t$ nd2 and pcna transcript levels, suggesting that MEK inhibition reduced both mitochondrial gene expression and cell proliferation (Fig. $6 \mathrm{D})$.

In conclusion, S727 phosphorylation connects mitochondrial transcription with cell proliferation and inhibitors of the MEK-ERK pathway affecting $\$ 727$ phosphorylation, such as PD98059, abrogate both processes.

Jak2 kinase maintains normal mtDNA transcription and proliferation in the PML and the intestine

After demonstrating that a) mitoSTAT3-driven mitochondrial transcription relies on both 
Y705 and S727 post-transcriptional phosphorylation, and b) that the consequential proliferation effect downstream of mitochondrial transcription requires functional MEK kinases, we decided to test the dependence of both mitochondrial transcription and cell proliferation on Jak2 Tyrosine-kinase activity, which promotes Y705 phosphorylation. WT embryos were therefore treated from 24 to 72 hpf with AG490, a specific inhibitor of Jak2 widely used as a JAK/STAT3 inhibitor (Park et al., 2014; Garbuz et al., 2014), and the expression of $m t \_n d 2$ was assessed by qRT-PCR. When observed at 72 hpf, AG490treated larvae displayed a significant reduction of $m t$ nd2 expression in the PML, the inner retina and the primordium of the intestine (Fig. $7 \mathrm{~A}$ (arrowheads)), while no significant decrease was present at $48 \mathrm{hpf}$ (Fig. 7 B; Fig. S6 A). In addition, proliferation activity was found to be significantly reduced in the PML of 72-hpf AG490-treated larvae as assayed by in situ hybridization using anti-pcna probe (Fig. 7 C, D).

We also investigated the effect of Jak2 inhibitor in the intestine, a highly proliferating tissue of zebrafish larvae, where $m t$ nd2 gene is strongly expressed between 3 and 6 days post fertilization (dpf) (Fig. 8 A). The activity of Stat3 in the intestine of zebrafish is consistent with the facts that a) the proliferative and survival effects of IL-6 in murine IECs (intestinal epithelial cells) is largely mediated by STAT3 (Grivennikov et al., 2009), b) that STAT3 is needed for small-intestine crypt stem cell survival, as revealed by conditional mutant mice (Matthews et al., 2011), and c) that Stat3-positive cells in zebrafish intestine represent a population of intestinal Wnt-responsive stem cells (Peron et al., 2020). Administration of 60 $\mu \mathrm{M}$ AG490 between 3 and $6 \mathrm{dpf}$ was able to significantly reduce mitochondrial transcription in the intestine of treated larvae with respect to DMSO treated controls (Fig. 8 A, B). Moreover, the treatment of larvae with AG490 caused a significant decrease in the number of intestinal proliferating cells (revealed by immunohistochemistry with anti-pH3 antibody) (Fig. 8 C, D) and resulted in flattening of the intestinal mucosa (Fig. 8 E, F). Taken together, these experiments demonstrate in vivo that phosphorylation of the Stat3 Y705 residue is required in zebrafish for normal mitochondrial transcription and downstream proliferation in the developing $\mathrm{TeO}$ and intestine.

\section{The zebrafish stat3/ ${ }^{-/}$null mutant displays impairment of mitochondrial transcription and cell proliferation in CNS and intestine}

To confirm data obtained by endogenous Stat3 chemical treatment with either MEK and Jak2 inhibitors, we used the zebrafish stat ${ }^{i a 23}$ mutant (from now on called stat $^{-/}$) (Peron 
et al., 2020), which is predicted to encode a premature stop codon at amino acid 456, thus lacking all functional domains including the dimerization domain and the transactivation domain, harbouring Y705 and S727 phosphorylation sites, respectively. As reported in Peron et al. (2020), these mutants die within one month of age and they can be obtained only after breeding between adult $s t a t 3^{+/}$zebrafish. We decided to test if the genetic ablation of zebrafish stat3 determines a reduction of $m t$ _nd2 in 48-hpf larvae. As reported in Fig. S6 B, no significant differences were detected by in situ hybridization against $m t \_n d 2$ in $s t a t 3^{+/+}$, stat $3^{+/}$, and stat $^{-/} 48$-hpf sibling larvae. This result is probably due to genetic compensation. To overcome this issue and to determine whether genetic ablation of stat3 alters mitochondrial transcription and cell proliferation in 48-hpf larvae, we decided to analyse stat3 "CRISPants" generated after injection of Cas9 protein and sgRNAs which target the antisense strand of exons 14, 22 and 23 of stat3 gene: this approach is employed to target a gene and silence its RNA transcription, according to the principles of classic CRISPR/Cas9 (Strutt et al., 2018). We evaluated the efficiency of stat3 targeting by injection of the $\operatorname{Tg}(7 x C R P-H u$.tk:EGFP) reporter line characterized in Peron et al. (2020). Results show that Stat3-dependent fluorescence of reporters is significantly dampened in CRISPants when compared to control larvae (Fig. 9 A-A'), while PCR analysis of the target confirmed that stat3 has been successfully mutagenised in exons 14, 22, and 23 (Fig. 9 A'). Notably, qRT-PCR analysis of stat3 and socs3a in CRISPants displayed a significant downregulation of both transcripts (Fig. 9 B,D). Hence, we decided to use CRISPants for the analysis of $m t$ nd2 and pcna expression levels. As reported in Fig. 9 E-F, both transcripts are significantly downregulated in stat3 CRISPants, confirming again that Stat3 is involved in mitochondrial transcription and cell proliferation. Interestingly, injection of MLS_mStat3_NES mRNA in CRISPants, while rescuing completely $m t \_n d 2$ and pcna transcript levels, does not restore the nuclear activities of Stat3 (Fig. 9 C,D,E,F).

In agreement with our previous results, when analysed at 6 dpf stat3 knock-out displays a significant and clear reduction of both $m t$ nd2 and pcna transcripts, endorsing the link between Stat3 mitochondrial functions and its role in the regulation of cell proliferation. Notably, about $70 \%$ of stat $^{-/-}$larvae display severe defects in the development of intestinal epithelium (Peron et al., 2020): as revealed by pHH3 immunostaining, intestinal mitoses are almost absent (Fig. 10 B-B') and the intestine fails to fold (Fig. 10 C-C'). These phenotypic alterations are almost identical to those induced by AG490 treatment (Fig. 8 
B,C). At $6 \mathrm{dpf}$ stat3 $^{-/}$larvae also show impaired CNS cell proliferation in the Telencephalon (Tel), the Diencephalon ( $\mathrm{Di})$ and the TeO, where Pcna is found to be reduced down to $15 \%$ with respect to stat $3^{+/}$siblings, supporting, once again, the requirement of Stat3 to maintain normal proliferation in the brain (Fig. $10 \mathrm{D}, \mathrm{E}$ ).

Interestingly, no overt structural alteration is present in intestinal or brain mitochondria of 6-dpf stat3 ${ }^{-/}$larvae analysed by TEM (Fig. S7 A). Moreover, in order to evaluate the amount of mitochondria, we crossed stat3 mutants with the Tg(CoxVIII-m/s:EGFP) transgenic line that expresses a mitochondria-localized form of enhanced GFP. No clear change in the total mitochondria volume was present in the intestine of stat $^{-/}$larvae with respect to stat $^{+/+}$sibling larvae (Fig. S7 B,C). Together with previous results, this highlights that mitoSTAT3 is only acting as regulator of mitochondrial transcription, without impacting on mitochondria biogenesis or homeostasis.

\section{DISCUSSION}

Using the zebrafish model and taking advantage of a STAT3 harbouring both a mitochondrial localization sequence and a nuclear export signal, we explored how mitoSTAT3 may act inside the mitochondrion. Interestingly, since mitochondrial mRNAs a) are reduced in stat3 ${ }^{i a 23 / i a 23}$ zebrafish null mutants and CRISPants b) are decreased in embryos treated with the Jak2 kinase inhibitor AG490, and c) the effect of MLS_Stat3_NES in promoting mitochondrial gene expression is abolished by Balapiravir (a mtRNA RNA polymerase inhibitor), our data strongly support, in vivo, a direct link between mitoSTAT3 activity and mitochondrial transcription. This is consistent with the mitochondrial transcriptional role of mitoSTAT3 found in vitro in murine ESCs, previously reported (Carbognin et al., 2016). On the other hand, quite surprisingly for a transcription factor, MLS_Stat3_NES mutated in its DNA-binding domain is still able to increase mitochondrial transcription. This result suggests that STAT3, differently from what hypothesized in Macias et al. (2014), does not regulate mtDNA transcription by binding STAT3 responsive elements located in the mtDNA, consistently with the differences between the eukaryotic and the prokaryotic transcriptional machineries operating in the nucleus and mitochondria, respectively. We previously reported that Stat3 binds mtDNA in ESCs (Carbognin et al. 2016), therefore we hypothesise that such binding is mediated by additional proteins whose identification will be the aim of future studies. 
One of the most fascinating aspects of mitochondria evolution is their progressive incorporation in the machinery of cell regulatory activities such as cell proliferation and apoptosis (Antico Arciuch et al., 2012). By showing that mitoSTAT3-driven mitochondrial transcription controls cell proliferation, at least in intestinal and tectal undifferentiated progenitor cells, our data partially answer the open questions about the mechanisms that synchronize mitochondrial and nuclear activities during cell proliferation.

Canonical STAT3 activation depends on different modifications, such as the phosphorylation at tyrosine 705 (Y705), that induces dimerization and translocation to the nucleus, and at serine 727 (S727), whose function has been reported to have unclear effects on STAT3 nuclear transcriptional activity (Decker et al., 2000; Huang et al., 2014). On the other hand, the post-translational modifications required for mitoSTAT3 import and activity in mitochondria have not been clearly dissected so far, although phosphorylation at S727 has been found to both activate OXPHOS complexes I and II, and suppress ROS production and cytochrome c release following ischemic injury (Meier \& Larner, 2014). More recently, STAT3 phosphorylation at S727 was also found to be required for STAT3mediated regulation of $\mathrm{ER} \mathrm{Ca}^{2+}$ fluxes and apoptosis through the regulation of the mitochondrial $\mathrm{Ca}^{2+}$ uptake (Avalle et al., 2019). We provide here in vivo evidence that phosphorylation of STAT3 Y705, being required for precise mitochondrial import of STAT3, is needed for STAT3-mediated mitochondrial gene expression, a result also confirmed in mouse ESCs. On the other hand, in accordance with the results obtained by Wegrzyn et al. (2009), we show that mitochondrial STAT3 transcriptional activity in vivo is totally dependent on phosphorylation of the ERK target S727. Experiments in mouse ESCs allowed us to clearly demonstrate that phosphorylated $S 727$ is not required for mitochondrial localization of STAT3 but, rather, for its activity once imported in the organelle. In vivo experiments performed in zebrafish larvae show that both mitoSTAT3mediated mtDNA transcription and cell proliferation are repressed by targeting $\$ 727$ with a MEK inhibitor.

Hence, by dissecting the roles of Y705 and S727 phosphorylation in the mitochondrial specific activity of STAT3 both in zebrafish larvae and mouse ESCs, our results add further insight into the specificity of mitochondrial STAT3 in the regulation of cellular processes, previously thought to be dependent exclusively on canonical (nuclear) STAT3. Together with the fact that mitochondrial STAT3 has been identified as a contributor to RAS-dependent cellular transformation (Gough et al., 2009), we support the idea of ERK- 
mitoSTAT3-mediated mitochondrial transcription might be a key process in cancer development, especially in the intestine, where we demonstrate here and in Peron et al., (2020) that cell proliferation is STAT3-dependent. Considering that, to date, the vast majority of STAT3-targeted cancer therapeutic approaches focus only on its canonical functions, our findings imply mitochondrial STAT3-specific transcriptional activity as a significant molecular mechanism to be targeted. 


\section{MATERIALS AND METHODS}

\section{Animal husbandry and lines}

Animals were staged and fed as described by Kimmel et al. (1995) and maintained in large scale aquaria systems.

Embryos were obtained by natural mating, raised at $28 \square^{\circ} \mathrm{C}$ in Petri dishes containing fish water (50X: $25 \square \mathrm{g}$ Instant Ocean, 39.25 $\square \mathrm{g} \mathrm{CaSO}_{4}$ and $5 \square \mathrm{g} \mathrm{NaHCO}_{3}$ for $1 \square \mathrm{L}$ ) and kept in a 12:12 light-dark (LD) cycle. All experimental procedures complied with European Legislation for the Protection of Animals used for Scientific Purposes (Directive 2010/63/EU).

stat ${ }^{i a 23}$ mutants and $\mathrm{Tg}(7 \times S t a t 3: E G F P)$ transgenic zebrafish are described in Peron et al. (2020). The Tg(CoxVIII-m/s:EGFP) transgenic zebrafish line is described in Martorano et al. (2019).

\section{Drug treatments}

The following chemical compounds were used: AG490 (T3434, Sigma Aldrich); PD98059 (PHZ1164, Thermo Fisher Scientific); Balapiravir (HY-10443, DBA). Before drug administration, a hole was made in the chorion of $8 \mathrm{hpf}$ embryos, while $24 \mathrm{hpf}$ embryos were dechorionated. All drugs were dissolved in DMSO and stored in small aliquots at $20^{\circ} \mathrm{C}$. $100 \mu \mathrm{M} \mathrm{AG} 490$ treatment was performed from 24 to $48 \mathrm{hpf}$ or from 24 to $72 \mathrm{hpf} .60$ $\mu \mathrm{M}$ AG490 was administered in 3-6 dpf treatments. $12.5 \mu \mathrm{M}$ PD98059 treatment was administered from 24 to $48 \mathrm{hpf} .50 \mu \mathrm{M}$ Balapiravir solution was administered from 8 to 48 hpf. After treatments, embryos were either anesthetized and fixed in 4\% paraformaldehyde (PFA) (158127, Sigma) in PBS for ISH, FISH and IHC or in TRI Reagent ${ }^{\circledR}$ (T9424, Sigma) for qRT-PCR analysis.

\section{CRISPRants generation}

sgRNA against exon 14 of stat3 gene was produced as described in Peron et al. (2020). sgRNAs against exon 22 and 23 of stat3 gene have been designed with CHOPCHOP software https://chopchop.rc.fas.harvard.edu, and provided by Synthego.

Cas9 protein (M0646, NEB) and sgRNAs against antisense of exons 14, 22 and 23 of stat3 genes were injected in 1-cell stage eggs. Subsequently, 48-hpf injected larvae were 
collected for DNA and RNA extraction and for imaging. Sequences of sgRNAs and of primer used for genotyping are listed in Table 1.

Table 1. List of sgRNAs sequences and primer used for genotyping (5'-3' sequences)

\begin{tabular}{|c|c|c|}
\hline \multicolumn{3}{|c|}{ sgRNA } \\
\hline Exon & Sequence & Reference \\
\hline 14 & GGUCGAUCUUAAGUCCUUGG & Peron et al. (2020) \\
\hline 22 & AGUGAGCUGCUUGGGAA & Thls paper \\
\hline 23 & AUGAGAGAGUCGAGCGUGCG & Thls paper \\
\hline \multicolumn{3}{|c|}{ Genotyping } \\
\hline Primer & Primer sequence & Reference \\
\hline stat3 ex14 f $\mathrm{W}$ & GGCCTCTCTGATAGTGACCG & Peron et al. (2020) \\
\hline $\operatorname{stat} 3 \operatorname{ex} 14 \mathrm{rv}$ & AGTTGTGCTTAGACGCGATC & Peron et al. (2020) \\
\hline stot3 ex22 fw & GTGTGTGTGTTAGGCAGGCT & Thls paper \\
\hline $\operatorname{stat} 3 \operatorname{ex} 22 r v$ & AGCTCCCTAATGCCTACCCA & Thls paper \\
\hline stat3 ex22 fw & TGCAGGACTAACTCTGGCAA & Thls paper \\
\hline $\operatorname{stot} 3 \operatorname{ex} 23 \mathrm{rv}$ & GCTTCGTTGTGCATGAGAGA & Thls paper \\
\hline$n r 3 c 1 f w$ & ACCACTTCAAGCGGACAGAG & Facchinello et al. (2017) \\
\hline$n r 3 c 1 r v$ & CCGGCTTCTGATCTTTCTGC & Facchinello et al. (2017) \\
\hline
\end{tabular}

\section{mRNAs synthesis and injection}

mStat3, mStat3_Y705F and mStat3_S727A CDSs were obtained from pCEP4-Stat3-WT, pCEP4-Stat3-Y705F, pCEP4-Stat3-S727A plasmids (a kind gift of the Poli Lab; Department of Molecular Biotechnology and Health Sciences, Molecular Biotechnology Center, University of Turin) and sub-cloned into a pCS2+ backbone using the In-Fusion® HD Cloning Kit (Clontech). MLS_mStat3_NES CDS, containing the murine Stat3 cDNA flanked by a Mitochondrial Localization Sequence (MLS) and a Nuclear Export Sequence (NES), was subcloned into a pCS2+ plasmid from a 70_pPB-CAG+MLS+Stat3+NES-pApgk-hph-2-2 plasmid by digestion with Xbal and BamHI. Mutated forms of 
MLS_mStat3_NES mRNA were obtained from pCS2+MLS_mStat3_NES by site-directed mutagenesis using the $Q 5 \AA$ Site-Directed Mutagenesis Kit (NEB); primers are indicated in Table 2.

mRNAs were in vitro transcribed using the mMESSAGE mMACHINE® SP6 Transcription Kit (Thermo Fisher Scientific) and purified using the RNA Clean and Concentrator kit (Zymo Research). A mix containing mRNA (30 ng/ $\mu \mathrm{L}$ for Stat3-WT, Stat3-Y705F, Stat3$S 727 A ; 50 \mathrm{ng} / \mu \mathrm{L}$ for MLS_Stat3_NES), Danieau injection Buffer and Phenol Red injection dye, was injected into 1-cell stage embryos.

Table 2. List of cloning-related primers (5'-3' sequences)

\begin{tabular}{|c|c|}
\hline Primer name & Primer sequence \\
\hline MLS_STAT3_NES_Y705F $\mathrm{W}$ & GCTGCCCCGTTCCTGAAGACC \\
\hline MLS_STAT3_NES_Y705FrV & ACTACCTGGGTCGGCTTC \\
\hline MLS_STAT3_NES_S727A $\mathrm{fW}$ & CCTGCCGATGGCCCCCCGCAC \\
\hline MLS_STAT3_NES_S727A rV & TCAATGGTATTGCTGCAGGTCGTTGGTGTC \\
\hline MLS STAT3_NES_LDNAbd fw & GGCGATCTCCAACATCTGTCAGATGC \\
\hline MLS_STAT3_NES__DNAbd $N$ & GCGGCTGGCAAGGAGTGGGTCTC \\
\hline
\end{tabular}

\section{mRNA isolation and quantitative real time reverse transcription PCR (qRT-PCR)}

For expression analysis, total RNA was extracted from pools of 15 7-dpf larvae or 3548 hpf embryos with TRIzol reagent (15596018, Thermo Fisher Scientific). mRNA was treated with RQ1 RNase-Free DNase (M6101, Promega) and then used for cDNA synthesis with Superscript III Reverse Transcriptase (18080-044, Invitrogen) according to the manufacturer's protocol. qPCRs were performed in triplicate with EvaGreen method using a Rotor-gene Q (Qiagen) and the 5x HOT FIREPol ${ }^{\circledR}$ EvaGreen® qPCR Mix Plus (08-3600001, Solis BioDyne) following the manufacturer's protocol. The cycling parameters were: $95^{\circ} \mathrm{C}$ for $14 \mathrm{~min}$, followed by 45 cycles at $95^{\circ} \mathrm{C}$ for $15 \mathrm{~s}, 60^{\circ} \mathrm{C}$ for $35 \mathrm{~s}$, and $72^{\circ} \mathrm{C}$ for $25 \mathrm{~s}$. Threshold cycles $(\mathrm{Ct})$ and dissociation curves were generated automatically by RotorGene $Q$ series software. Sequences of specific primers used in this work for qRT-PCR and RT-PCR are listed in Table 3. Primers were designed using the software Primer 3 (http://bioinfo.ut.ee/primer3-0.4.0/input.htm). Sample Ct values were normalized with Ct values from zebrafish gapdh and results were obtained following the method described in Livak and Schmittgen (2001). 
Table 3. List of qRT-PCR and RT-PCR primers (5'-3' sequences)

\begin{tabular}{|c|c|c|}
\hline Gene & Forward primer sequence & Reverse primer sequence \\
\hline $7 m t$ nd2 & GCAGTAGAAGCCACCACAAA & GCTAGACCGATTITGAGAGCC \\
\hline Lgapdh & GTGGAGTCTACTGGTGTCTIC & GTGCAGGAGGCATTGCTTACA \\
\hline zecna & CE TGGCACTGGTC ITGAA & GGCACACGAGATCATGACAG \\
\hline $2 \operatorname{socs} 3 a$ & GGAMGACAMGAGCCGAGACT & GCGATACACACCNMCCETS \\
\hline nSocs.? & ATTCGCTTCGGGACTAGC & AACTGCTGTGGGTGACCAT \\
\hline nstat3 & TGTTGGAGCAGCATCTTCAG & GAGGTTCTCOACCACCTTCA \\
\hline nbactin & CTAAGGCCAACCGTGAAAAG & ACCAGAGGGCATACAGGGACA \\
\hline
\end{tabular}

\section{Immunoblotting and mitochondria isolation}

Immunoblotting was performed as previously described in Carbognin et al. (2016). The following antibodies were used: anti-STAT3 mouse monoclonal (9139, Cell Signalling) (1:1000), anti-GAPDH mouse monoclonal (MAB374, Millipore) (1:1000), anti-VDAC1 rabbit polyclonal (ab15895, Abcam) (1:1000), anti-Lamin (sc-6217, Santa Cruz) (1:1000), antibActin mouse monoclonal (MA1-744, Invitrogen) (1:10000), anti-pSTAT3 S727 rabbit monoclonal (9134, Cell Signalling). Mitochondria from mouse ESCs were isolated using Mitochondria isolation kit (89874, Thermo Scientific).

\section{3,3'-Diaminobenzidine staining}

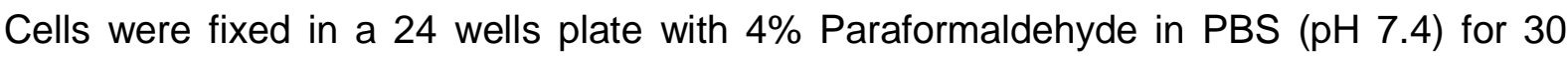
minutes at RT (room temperature). After fixation cells were washed 5 times with PBS (5 minutes each), blocked and permeabilized with $5 \%$ normal goat serum and $0.1 \%$ saponin in PBS for $30 \mathrm{~min}$, and then incubated with primary antibody anti-STAT3 mouse monoclonal (9139, Cell Signalling) $\mathrm{ON}$ at $4^{\circ} \mathrm{C}$ in PBS 5\% normal goat serum and $0.05 \%$ saponin. After 5 washes with PBS (5 minutes each), cells were incubated with HRPconjugated Fab fragments of the secondary antibody for 2 hours at RT. After 5 washes, cells were incubated in the DAB solution $(0.01 \mathrm{gr}$ DAB in $20 \mathrm{~mL}$ TRIS-HCl buffer plus $30 \%$ $\mathrm{H}_{2} \mathrm{O}_{2}$ solution just before use). Subsequently the samples ware postfixed with $1 \%$ osmium tetroxide plus potassium ferrocyanide $1 \%$ in $0.1 \mathrm{M}$ sodium cacodylate buffer for 1 hour at $4^{\circ} \mathrm{C}$. After three water washes, samples were dehydrated in a graded ethanol series and embedded in an epoxy resin (Sigma-Aldrich). Ultrathin sections (60-70 nm) were obtained with an Ultrotome $\mathrm{V}$ (LKB) ultramicrotome, counterstained with uranyl acetate and lead citrate and viewed with a Tecnai G2 (FEl) transmission electron microscope operating at 
$100 \mathrm{kV}$. Images were captured with a Veleta (Olympus Soft Imaging System) digital camera.

\section{Immunofluorescence}

ESCs were grown and transfected as described by Carbognin et al. (2016). For IF ESCs were fixed for $10 \mathrm{~min}$ in cold methanol at $-20^{\circ} \mathrm{C}$, washed in TBS, permeabilized for $10 \mathrm{~min}$ with TBST $+0.3 \%$ Triton X-100 at RT, and blocked for 45 min in TBS $+3 \%$ goat serum at RT. The cells were incubated overnight at $4{ }^{\circ} \mathrm{C}$ with primary antibodies (anti-STAT3 mouse monoclonal (9139, Cell Signalling) (1:100); anti-ATAD3A rabbit monoclonal (224485, AB-Biotechnologies) (1:100). After washing with TBS, the cells were incubated with secondary antibodies (Alexa, Life Technologies) for $30 \mathrm{~min}$ at RT. Cells were mounted with ProLong® Gold Antifade Mountant with DAPI (P36941, Life Technologies) or HOECHST 33342 (62249, Thermo Fisher) where specified. Images were acquired with a Leica SP2 confocal microscope equipped with a CCD camera.

\section{In situ hybridization}

Whole mount RNA in situ hybridization on zebrafish embryos was performed as previously described (Thisse et al., 1993). It is worth mentioning that treated and control embryos were hybridized together. stat3 probe was obtained by PCR amplification from embryos cDNA using stat3_probe-fw (5'-TGCCACCAACATCCTAGTGT-3') and stat3_probe-rv (5'GCTTGTTTGCACTTTTGACTGA-3') primers. mt_nd2 probe was obtained by PCR amplification from embryos cDNA using mt_nd2-fw (5'-GCAGTAGAAGCCACCACAAA-3') and mt_nd2-rv (5'-GGAATGCCGCGGATGTTATA-3') primers. pcna probe was obtained as described by Baumgart et al. (2014). sox9b probe was obtained as described by Chiang et al. (2001). her5 probe was obtained as described by Bally-Cuif, et al. (2000). her4 probe was obtained as described by Takke et al. (1999). Fluorescence in situ hybridization was performed with FastBlue or TSA-amplification kit (Invitrogen) as described by Lauter et al. (2011).

\section{Transmission Electron Microscopy analysis}


Larvae were anesthetised and fixed with $2.5 \%$ glutaraldehyde in $0.1 \mathrm{M}$ sodium cacodylate buffer. After that, samples were dehydrated, embedded in epoxy resin, and prepared according to standard protocols by the Trasmission Electron Microscopy facility at the Department of Biology (University of Padova).

\section{Statistical analysis}

Statistical analysis was performed with Graph Pad Prism V6.0. Data are presented as the means \pm SEM and statistical analysis was determined by unpaired two tailed Student's ttest. The $p$-values are indicated with the following symbols: ${ }^{*}, p<0.05 ;{ }^{* *}, p<0.01 ;{ }^{* *}, p<$ $0.001 ;{ }^{* * *}, p<0.0001$. For quantitative analysis, the sample size for each experiment was calculated assuming a Confidence Level of 95\% (z-score 1,.96), a standard deviation of 0.5 and a Confidence Interval (margin of error) of $5 \%$.

\section{Acknowledgments}

We would like to thank Dr Luigi Pivotti, Dr Martina Milanetto, Dr Carlo Zatti, Dr Ludovico Scenna, and Mrs Shkendy Iljazi for their professional help in managing the Padua Zebrafish Facility, and Dr Andrea Vettori for his technical support. We are also grateful to Dr Valeria Poli and Dr Annalisa Camporeale for their kind gift of murine STAT3-encoding plasmids and their criticisms.

The work was fully supported by the AIRC grant IG 201719928 (to F.A.), with the contribution of the Telethon grant GGP19287 (to F.A.).

\section{Authors contribution}

MP:acquisition, analysis, interpretation of data, drafting the work.

GM: acquisition, analysis, interpretation of data.

AD: acquisition, analysis, interpretation of data, drafting the work, critical revision.

LM: acquisition, analysis.

RMB: acquisition, analysis, interpretation of data, critical revision.

NF: acquisition, analysis, interpretation of data.

AT: acquisition, analysis.

NT: interpretation of data, drafting the work, critical revision.

GM: interpretation of data, drafting the work, critical revision. 
bioRxiv preprint doi: https://doi.org/10.1101/2020.07.17.208264; this version posted January 27, 2021. The copyright holder for this preprint (which was not certified by peer review) is the author/funder, who has granted bioRxiv a license to display the preprint in perpetuity. It is made available under aCC-BY-NC-ND 4.0 International license.

FA: analysis, interpretation of data, drafting the work, critical revision.

\section{Competing interests}

The authors declare no competing or financial interests. 


\section{REFERENCES}

Alessi D.R., Cuenda A., Cohen P., Dudley D.T., Saltiel A.R. (1995). PD 098059 is a specific inhibitor of the activation of mitogen-activated protein kinase kinase in vitro and in vivo. J Biol Chem. 270(46):27489-94.

Antico Arciuch V.G., Elguero M.E., Poderoso J.J., Carreras M.C. (2012). Mitochondrial regulation of cell cycle and proliferation. Antioxid Redox Signal. 16(10):1150-80.

Avalle L., Camporeale A., Morciano G., Caroccia N., Ghetti E., Orecchia V., Viavattene D., Giorgi C., Pinton P., Poli V. (2019). STAT3 localizes to the ER, acting as a gatekeeper for ER-mitochondrion $\mathrm{Ca} 2+$ fluxes and apoptotic responses. Cell Death Differ. May;26(5):932-942.

Bally-Cuif, L., Goutel, C., Wassef, M., Wurst, W., \& Rosa, F. (2000). Coregulation of anterior and posterior mesendodermal development by a hairy-related transcriptional repressor. Genes \& development. 14(13), 1664-77.

Baumgart, M., Groth, M., Priebe, S., Savino, A., Testa, G., Dix, A., Ripa, R., Spallotta, F., Gaetano, C., Ori, M., Terzibasi Tozzini, E., Guthke, R., Platzer, M. and Cellerino, A. (2014). RNA-seq of the aging brain in the short-lived fish N. furzeri - conserved pathways and novel genes associated with neurogenesis. Aging Cell. 13: 965-974.

Becker S., Groner B., Müller C.W. (1998). Three-dimensional structure of the Stat3beta homodimer bound to DNA. Nature. 394:145-151 10.1038/28101

Burdon T., Chambers I., Stracey C., Niwa H., Smith A. (1999). Signaling mechanisms regulating self-renewal and differentiation of pluripotent embryonic stem cells. Cells Tissues Organs. 165(3-4):131-43.

Carbognin, E., Betto, R. M., Soriano, M. E., Smith, A. G. and Martello, G. (2016). Stat3 Promotes Mitochondrial Transcription and Oxidative Respiration during Maintenance and Induction of Naive Pluripotency. EMBO J. 35, 618-634.

Chiang E.F.L., Pai C.I., Wyatt M., Yan Y.L., Postlethwait J., and Chung B.C. (2001). Two sox9 genes on duplicated zebrafish chromosomes: Expression of similar transcription activators in distinct sites. Dev Bio. 231: 149-163.

Decker T., \& Kovarik P. (2000). Serine phosphorylation of STATs. Oncogene. 19: 26282637.

Facchinello N., Skobo T., Meneghetti G., Colletti E., Dinarello A., Tiso N., Costa R., Gioacchini G.,Carnevali O., Argenton F., Dalla Valle L. (2017) nr3c1 null mutant zebrafish are viable and reveal DNA-binding-independent activities of the glucocorticoid 
receptor. Scientific reports. 7: 4371.

Feng J.Y., Xu Y., Barauskas O., Perry J.K., Ahmadyar S., Stepan G., Yu H., Babusis D., Park Y., McCutcheon K., Perron M., Schultz B.E., Sakowicz R., Ray A.S. (2015) Role of Mitochondrial RNA Polymerase in the Toxicity of Nucleotide Inhibitors of Hepatitis C Virus. Antimicrob Agents Chemother. 60(2):806-17.

Fouse S.D., Costello J.F. (2013). Cancer Stem Cells Activate STAT3 the EZ Way. Cancer Cell. 23(6). 711-713.

Gagnon J.A., Valen E., Thyme S.B., Huang P., Ahkmetova L., Pauli A., et al. (2014). Efficient Mutagenesis by Cas9 Protein-Mediated Oligonucleotide Insertion and LargeScale Assessment of Single-Guide RNAs. PLoS ONE. 9(5): e98186.

Ghoshal S., Fuchs B. C., \& Tanabe K. K. (2016). STAT3 is a key transcriptional regulator of cancer stem cell marker CD133 in HCC. Hepatobiliary Surgery and Nutrition. 5(3), 201203.

Gough D.J., Corlett A., Schlessinger K., Wegrzyn J., Larner A.C., Levy DE. (2009). Mitochondrial STAT3 supports Ras-dependent oncogenic transformation. Science. 324(5935):1713-6.

Gough D.J., Koetz L., Levy D.E. (2013) The MEK-ERK Pathway Is Necessary for Serine Phosphorylation of Mitochondrial STAT3 and Ras-MediatedTransformation. PLOS ONE 8(11): e83395.

Grivennikov, S., Karin, E., Terzic, J., Mucida, D., Yu, G. Y., Vallabhapurapu, S., Scheller, J., Rose-John, S., Cheroutre, H., Eckmann, L. et al. (2009). IL-6 and Stat3 are Required for Survival of Intestinal Epithelial Cells and Development of Colitis-Associated Cancer. Cancer. Cell. 15, 103-113.

Gurbuz V., Konac E., Varol N., Yilmaz A., Gurocak S., Menevse S., Sozen S. (2014). Effects of AG490 and S3I-201 on regulation of the JAK/STAT3 signaling pathway in relation to angiogenesis in TRAIL-resistant prostate cancer cells in vitro. Oncol Lett. 7(3): 755-763.

Horvath C.M., Wen Z., Darnell J.E., Jr. (1995). A STAT protein domain that determines DNA sequence recognition suggests a novel DNA-binding domain. Genes Dev. 9:984994.

Huang G., Yan H., Ye S., Tong C., Ying Q.L. (2014). STAT3 phosphorylation at tyrosine 705 and serine 727 differentially regulates mouse ESC fates. Stem Cells. 32:1149-1160.

Johnston P.A., Grandis J.R. (2011). STAT3 signaling: anticancer strategies and challenges. Mol Interv. 11(1):18-26. 
Kimmel C.B., Ballard W.W., Kimmel S.R., Ullmann B., Schilling, T.F. (1995), Stages of embryonic development of the zebrafish. Dev. Dyn. 203: 253-310.

Lauter G., Söll I., Hauptmann G. (2011). Two-color fluorescent in situ hybridization in the embryonic zebrafish brain using differential detection systems. BMC developmental biology. 11,43.

Liu Y., Sepich D.S., Solnica-Krezel L. (2017) Stat3/Cdc25a-dependent cell proliferation promotes embryonic axis extension during zebrafish gastrulation. PLoS Genet. 13(2): e1006564. https://doi.org/10.1371/journal.pgen.1006564

Livak K.J., \& Schmittgen B.M. (2001) Analysis of relative gene expression data using real-time quantitative PCR and the 2(-Delta Delta C(T)) method. Methods. 25(4): 402-8.

Macias E., Rao D., Carbajal S., Kiguchi K. and DiGiovanni, J. (2014). Stat3 Binds to mtDNA and Regulates Mitochondrial Gene Expression in Keratinocytes. J. Invest. Dermatol. 134, 1971-1980.

Mantel C., Messina-Graham S., Moh A., Cooper S., Hangoc G., Fu X.Y., Broxmeyer H. E. (2012). Mouse hematopoietic cell-targeted STAT3 deletion: stem/progenitor cell defects, mitochondrial dysfunction, ROS overproduction, and a rapid aging-like phenotype. Blood. 120(13), 2589-99.

Martello G., Bertone P., Smith A. (2013) Identification of the missing pluripotency mediator downstream of leukaemia inhibitory factor. EMBO J. 32(19):2561-74.

Martorano L., Peron M., Laquatra C., Lidron E., Facchinello N., Meneghetti G., Tiso N., Rasola A., Ghezzi D., Argenton F. (2019) The zebrafish orthologue of the human hepatocerebral disease gene MPV17 plays pleiotropic roles in mitochondria. Dis Model Mech. 12(3): dmm0372226.

Matsuda T., Nakamura T., Nakao K., Arai T., Katsuki M., Heike T., Yokota T. (1999). STAT3 activation is sufficient to maintain an undifferentiated state of mouse embryonic stem cells. EMBO J. 18(15):4261-9.

Matthews J.R., Sansom O.J. and Clarke A.R. (2011). Absolute Requirement for STAT3 Function in Small-Intestine Crypt Stem Cell Survival. Cell Death Differ. 18, 1934-1943.

Meier J.A., Larner A.C. (2014). Toward a new STATe: the role of STATs in mitochondrial function. Seminars in immunology, 26(1), 20-8.

Mohr A., Fahrenkamp D., Rinis N., Muller-Newen G. (2013) Dominant-negative activity of the STAT3-Y705F mutant depends on the N-terminal domain. Cell Commun Signal. 11: 83. 
Ni C., Hsieh H., Chao Y., Wang D.L. (2004). Interleukin-6-induced JAK2/STAT3 signaling pathway in endothelial cells is suppressed by hemodynamic flow. American Journal of Physiology. Cell Physiology. 287(3) C771-C780.

Oates A.C., Wollberg P., Pratt S.J., Paw B.H., Johnson S.L., Ho R.K., Postlrthwait J.H., Zon L.I., Wilks A.F. (1999). Zebrafish stat3 is expressed in restricted tissues during embryogenesis and stat1 rescues cytokine signaling in a STAT1-deficient human cell line. Dev Dyn. 215:352-370.

O'Shea J.J., Schwartz D.M., Villarino A.V., Gadina M., Mclnnes I.B., Laurence A. (2015). The JAK-STAT pathway: impact on human disease and therapeutic intervention. Annu Rev Med. 66:311-28.

Park J.S., Lee J., Lim M.A., Kim E.K., Kim S.M., Ryu J.G., Lee J.H., Kwok S.K., Park K.S., Kim H.Y., Park S.H., Cho M.L. (2014) JAK2-STAT3 blockade by AG490 suppresses autoimmune arthritis in mice via reciprocal regulation of regulatory T Cells and Th17 cells. J Immunol. May 1;192(9):4417-24.

Peron M., Dinarello A., Meneghetti G., Martorano L., Facchinello N., Vettori A., Licciardello G., Tiso N., Argenton F. (2020) The stem-like STAT3-responsive cells of zebrafish intestine are WNT/ß-catenin dependent. Development. 147(12): dev188987.

Qin H.R., Kim H.J., Kim J.Y., Hurt E.M., Klarmann G.J., Kawasaki B.T., Duhagon Serrat M.A., Farrar W.L. (2008). Activation of signal transducer and activator of transcription 3 through a phosphomimetic serine 727 promotes prostate tumorigenesis independent of tyrosine 705 phosphorylation. Cancer research. 68(19), 7736-41.

Shi X., Zhang H., Paddon H., Lee G., Cao X., Pelech S. (2006). Phosphorylation of STAT3 serine-727 by cyclin-dependent kinase 1 is critical for nocodazole-induced mitotic arrest. Biochemistry. 45:5857-5867.

Smith A.G., Heat J.K., Donaldson D.D., Wong G.G., Moreau J., Stahl M., Rogers D. (1988) Inhibition of pluripotential embryonic stem cell differentiation by purified polypeptides. Nature. 336(6200): 688-690.

Strutt S.C., Torrez R.M., Kaya E., Negrete O.A., Doudna J.A. (2018) RNA-dependent RNA targeting by CRISPR-Cas9. eLife. 7: e32724.

Szczepanek K., Chen, Q., Derecka M., Salloum F.N., Zhang Q., Szelag M., Cichy J., Kukreja R.C., Dulak J., Lesnefsky E.J., et al. (2011). Mitochondrial-targeted signal transducer and activator of transcription 3 (stat3) protects against ischemia-induced changes in the electron transport chain and the generation of reactive oxygen species. $J$. Biol. Chem. 286,29610-29620. 
Taanman, J. (1999). The mitochondrial genome: structure, transcription, translation and replication. Biochimica et Biophysica Acta-Bioenergetics. 1410(2), 103-123.

Takke C., Dornseifer P., v Weizsäcker E., Campos-Ortega J.A. (1999). her4, A zebrafish homologue of the Drosophila neurogenic gene $\mathrm{E}(\mathrm{spl})$, is a target of NOTCH signalling. Development. 126: 1811-1821.

Thisse B., Pflumio S., Fürthauer M., Loppin B., Heyer V., Degrave A., Woehl R., Lux A., Steffan T., Charbonnier X.Q. and Thisse C. (2001) Expression of the zebrafish genome during embryogenesis (NIH R01 RR15402). ZFIN Direct Data Submission. (http://zfin.org)

Tian Z.J., An W. (2004) ERK1/2 contributes negative regulation to STAT3 activity in HSStransfected HepG2 cells. Cell Res. Apr;14(2):141-7.

Wang J., Zhou M., Jin X., Li B., Wang C., Zhang Q., Liao M., Hu X., Yang M. (2019) Glycochenodeoxycholate induces cell survival and chemoresistance via phosphorylation of STAT3 at Ser727 site in HCC. J Cell Physiol. 2019;1-12.

Wegrzyn J., Potla R., Chwae Y.J., Sepuri N.B., Zhang Q., Koeck T., Derecka M., Szczepanek K., Szelag M., Gornicka A., Moh A., Moghaddas S., Chen Q., Bobbili S., Cichy J., Dulak J., Baker D.P., Wolfman A., Stuehr D., Hassan M.O., Fu X.Y., Avadhani N., Drake J.I., Fawcett P., Lesnefsky E.J., Larner A.C. (2009). Function of mitochondrial Stat3 in cellular respiration. Science. 323(5915):793-7.

Wei W., Tweardy D.J., Zhang M., Zhang X., Landua J., Petrovic I., Bu W., Roarty K., Hilsenbeck S.G., Rosen J.M., Lewis M.T. (2014). STAT3 signaling is activated preferentially in tumor-initiating cells in claudin-low models of human breast cancer. Stem Cells. 32: 2571-2582. 


\section{FIGURE LEGENDS}

Fig. 1: Stat3 mRNA is co-expressed with proliferation and mtDNA transcription markers in the TeO of zebrafish embryos. Whole mount in situ hybridization (WISH) on 48-hpf zebrafish WT embryos using pcna (dark green frame and outline), mt_nd2 (light green frame and outline), and stat3 (yellow frame and outline) antisense mRNA probes shows co expression of the three transcripts in the PML region of the TeO; $r=$ retina; $P M L=$ Peripheral Midbrain Layer.

\section{Fig. 2: mitoSTAT3 regulates proliferation through mitochondrial DNA transcription.}

A-A": WISH with anti-mt_nd2 mRNA probe representing mitochondrial gene transcription in: uninjected embryos (A); embryos injected with MLS_mStat3_NES mRNA (A'); MLS_mStat3_NES mRNA injected embryos treated with $50 \mu \mathrm{M}$ Balapiravir (A"). B-B": Fluorescent in situ hybridization (FISH) with pcna probe in the $\mathrm{TeO}$ of: uninjected embryos (B); embryos injected with MLS_mStat3_NES mRNA (B'); and injected embryos treated with $50 \mu \mathrm{M}$ Balapiravir (B"). C: qRT-PCR showing $m$ t_nd2 gene expression after injection of MLS_mStat3_NES mRNA and treatment with Balapiravir at 48 hours post injection (hpi); zgapdh was used as internal control ( $p$-values $=0.0007 ; 0.0005)$. D: Fluorescence quantification of pcna mRNA expression in the TeO $(n=12)$ (p-values $=<0.0001 ; 0.0108$; 0.0122). E: Relative amount of mtDNA in embryos injected with MLS_mStat3_NES mRNA and uninjected controls at $48 \mathrm{hpf}$. Mean dCt values were calculated as Ct of $m t$ nd1 (mitochondrial encoded gene) minus Ct of polg1 (nuclear encoded gene) ( $p$-value= 0.3295). Statistical analysis was performed by unpaired t-test on 3 independent biological samples (where $n$ not specified). ns: not significant; ${ }^{\star} p<0.05$; ${ }^{* *} p<0.01$; ${ }^{* \star *} p<0.001$; error bars=SEM.

Fig. 3: Mutation of Stat3 DBD of does not affect its mitochondrial activities. A-A': qRT-PCR showing $m t$ nd2 gene expression after injection of MLS_mStat3_NES or MLS_mStat3_LDNAbd_NES mRNA in 48-hpf embryos; zgapdh was used as internal control ( $p$-values $=0.0184 ; 0.0093$ ). B: immunofluorescence on ESCs transiently transfected with MLS_mStat3_NES or MLS_mStat3_LDNAbd_NES and stained with antiSTAT3 (green), anti-ATAD3 (red) Ab and DAPI (blue). Scale bar: $200 \mu \mathrm{m}$. Statistical analysis in C-F was performed by unpaired t-test on 3 independent biological samples 
(where n not specified). ns: not significant; ${ }^{*} \mathrm{p}<0.05 ;{ }^{* *} \mathrm{p}<0.01$; error bars $=\mathrm{SEM}$.

Fig. 4: mitoSTAT3 transcriptional activity relies on both $\mathrm{S727}$ and Y705

phosphorylations. A: FISH with $m t$ nd2 probe in the TeO of 48-hpf embryos injected with mRNA encoding the indicated isoforms of $m$ Stat3. B: Fluorescence quantification of $m t$ nd2 mRNA expression in the TeO $(n=10)$ (p-values $=0.0074 ; 0.0307 ; 0.0023)$. C: RTPCR analysis of $m S t a t 3$ transcripts detected at $48 \mathrm{hpf} / \mathrm{hpi}$ in embryos injected with the indicated form of mStat3 mRNA; zgapdh was used as internal control. D: qRT-PCR analysis of $m t \_n d 2$ transcript levels at $48 \mathrm{hpf} / \mathrm{hpi}$ normalized to $z g a p d h$ ( $\mathrm{p}$ values $=0.0888$; $0.1899 ; 0.8334)$. E: RT-PCR analysis of MLS_mStat3_NES transcripts detected at 48 $\mathrm{hpf} / \mathrm{hpi}$ in embryos injected with indicated form of mitochondria-targeted mStat3 mRNA; zgapdh was used as internal control. F: qRT-PCR analysis of $m t \_n d 2$ transcript levels at $48 \mathrm{hpf} / \mathrm{hpi} \mathrm{normalized} \mathrm{to} \mathrm{zgapdh} \mathrm{(} \mathrm{p}$ values $=0.0184 ; 0.0355 ; 0.5846$ ). Statistical analysis was performed by unpaired t-test on 3 independent biological samples (where $n$ not specified). ns: not significant; ${ }^{*} p<0.05 ;{ }^{* *} p<0.01$; error bars $=S E M$.

Fig. 5: Y705 phosphorylation is needed for the correct localization of STAT3 in the mitochondrion. A: immunofluorescence with anti-STAT3 and anti-ATAD3 Ab on ESCs transient transfected with either mStat3, mStat3 Y705F or MLS_mStat3_NES Y705F. Arrows indicate the colocalization of ATAD and STAT3. Scale bar: $200 \mu \mathrm{m}$. B: western blot of total STAT3 in ESCs extracts, $\beta$-actin was used as a loading control. C: western blot of mitochondrial STAT3 from ESCs mitochondrial extracts; VDAC1 was used as a mitochondrial loading control, Lamin was used as a control for nuclear contamination. D: representative pictures of DAB immunohistochemistry on ESCs acquired with TEM; positive signal is black and negative is white. Arrows indicate mitochondria. Cristae are positive in Stat3 WT and MLS_Stat3_NES transfected cells.

Fig. 6: mitoSTAT3-dependent activation of cell proliferation in the TeO depends on S727 phosphorylation. A-A': Representative pictures of WISH performed with an antipcna probe on 48-hpf uninjected larvae, larvae injected with MLS_mStat3_NES and MLS_mStat3_NES S727A mRNAs (A). Fluorescence quantification of pcna mRNA expression in the TeO $(n=12)(p$-values $=<0.0001 ; 0.0108 ; 0.0122)\left(\mathbf{A}^{\prime}\right) . \mathbf{B}$ :

immunofluorescence with anti-STAT3 and anti-ATAD3 Ab on ESCs Stat3 -/- transiently 
transfected with the constructs encoding: $m S t a t 3, M L S \_m S t a t 3 \_N E S, M L S \_m S t a t 3 \_N E S$ $S 727 A$ or mStat3. Arrows indicate the colocalization of ATAD and STAT3. Scale bar: 200 $\mu \mathrm{m}$. C: western blot of mitochondrial STAT3 from ESCs mitochondrial extracts; VDAC1 was used as a mitochondrial loading control, Lamin was used as a nuclear loading control. D: qRT-PCR analysis of $m t \_n d 2$ and pcna on 48-hpf larvae treated with either PD98059 $12.5 \mu \mathrm{M}$ or DMSO. Statistical analysis was performed by unpaired t-test on 3 independent biological samples (where $n$ not specified). ${ }^{\star} p<0.05$; ${ }^{* \star *} p<0.0001$; error bars $=S E M$.

Fig. 7: JAK inhibition impairs normal mitochondrial transcription and cell proliferation in the TeO of 72-hpf embryos. A: WISH with anti-mt_nd2 mRNA probe on 72-hpf embryos treated with $100 \mu \mathrm{M}$ AG490 from 24-72 hpf and DMSO treated controls.

B: relative $m t$ nd2 transcript expression assayed by qRT-PCR in 48- and 72-hpf embryos treated with $100 \mu \mathrm{M}$ AG490 and DMSO treated controls starting from $24 \mathrm{hpf}$; zgapdh was used as internal control ( $p$-values $=0.6261 ; 0.0060$ ). C: $\mathrm{FISH}$ with anti-pcna probe in the TeO of 72-hpf embryos treated with $100 \mu \mathrm{M}$ AG490 from 24 to $72 \mathrm{hpf}$ and DMSO treated controls. D: Fluorescence quantification of pcna mRNA expression in the $\mathrm{TeO}(n=6)(p$ value $=0.0003$ ). Statistical analysis was performed by unpaired t-test on 3 independent biological samples (where $n$ not specified). ns: not significant; ${ }^{* *} p<0,01$; ${ }^{* *} p<0.001$; error bars $=$ SEM.

Fig. 8: JAK inhibition impairs normal mitochondrial transcription and cell proliferation in the intestine of 6-dpf larvae. A: WISH with anti-mt_nd2 mRNA probe on 6-dpf larvae treated with $60 \mu \mathrm{M}$ AG490 from 24-72 hpf and DMSO treated controls; zoom on the intestine. B: Quantification of $m t \_n d 2$ mRNA expression in the intestine $(n=30)(p-$ value $=0.0240)$. C: phospho-Histone-H3 $(\mathrm{pH} 3)$ immunostaining of 6-dpf AG490 treated larvae and DMSO treated controls; zoom on the intestine; $(\mathrm{pH} 3$ positive cells=arrowheads). D: Quantification of the number of AG490 and DMSO treated larvae displaying intestinal proliferation $(n=15)$ ( $p$-value=0.0026). E: AG490 treated larvae showing loss of folding in intestinal mucosa. F: Graph showing the dimension of mucosal thickness in both DMSO and AG490 6-dpf treated larvae $(n=18)$ ( $p$-value=0,0001). Statistical analysis was performed by unpaired test on indicated number of samples; ${ }^{*} \mathrm{p}<0.05 ;{ }^{* *} \mathrm{p}<0.01$; ${ }^{* *} \mathrm{p}<0.001$; error bars $=\mathrm{SEM}$.

Fig. 9: stat3 CRISPRants show reduced mitochondrial transcription that is rescued 
by mitochondrial Stat3. A-A": Representative pictures of 48-hpf $T g$ (7xStat3:EGFP) transgenic zebrafish larvae. Fluorescent quantification of TeO of control and CRISPRant zebrafish larvae. PCR amplification of the stat3 gene on DNA extracts from control and CRISPRant larvae ( $n r 3 c 1$ gene is used as an internal control). B: qRT-PCR against stat3 in 48-hpf control, CRISPRants and CRISPRants + MLS_mStat3_NES mRNA zebrafish larvae. C: qRT-PCR against Stat3 in 48-hpf control, CRISPRants and CRISPRants + MLS_mStat3_NES mRNA zebrafish larvae. D: qRT-PCR against socs3a in 48-hpf control, CRISPRants and CRISPRants+MLS_mStat3_NES mRNA zebrafish larvae. E: qRT-PCR against $m t$ nd2 in 48-hpf control, CRISPRants and CRISPRants+MLS_mStat3_NES mRNA zebrafish larvae. F: qRT-PCR against pcna in 48-hpf control, CRISPRants and CRISPRants+MLS_mStat3_NES mRNA zebrafish larvae. Statistical analysis was performed by unpaired t-test on 3 independent biological samples (where $n$ not specified). ${ }^{*} p<0.05 ;{ }^{* *} p<0.01 ;{ }^{* *} p<0.001$; error bars=SEM.

Fig. 10: stat3 KO impairs normal mitochondrial transcription and cell proliferation in the intestine and brain of 6-dpf zebrafish larvae. A: Relative mRNA expression of $m t \_n d 2$ and pcna transcripts assayed by qRT-PCR in homogenized stat $3^{-/}$and WT siblings at $6 \mathrm{dpf} ; z g a p d h$ was used as internal control ( $p$ values $=0.0358 ; 0.0182)$. B-B': phospho-Histone-H3 (pH3) immunostaining of stat3 ${ }^{-/}$and WT siblings at $6 \mathrm{dpf}$; zoom on the intestine. (pH3 positive cells=arrowheads). C-C': EE staining on WT and stat3 ${ }^{-/}$mutant sections at 6 dpf shows the complete loss of folding in the mutant intestinal epithelium. D: IF with anti-PCNA Ab on 6-dpf stat3 ${ }^{-/-}$mutants showing decrease of fluorescence in the CNS (Tel= telencephalon; Di: diencephalon; TeO: tectum opticum). E: Fluorescence quantification of PCNA protein on lateral sections of 6-dpf stat3/- mutants and WT siblings; zoom on the head $(n=8)$ ( $p$-value $<0.0001$ ). Statistical analysis was performed by unpaired t-test on 3 independent biological samples (where $n$ not specified). ${ }^{*} p<0.05$; ${ }^{* * *} p<0.0001$; error bars=SEM.

\section{Fig. S1: Validation of the MLS_Stat3_NES construct in murine Embryonic Stem}

Cells. A: Western blot for total STAT3 on Stat3 ${ }^{+/+}$, Stat3 ${ }^{-/}$and MLS_Stat3_NES cells. Note the shift in molecular weight due to the presence of MLS and NES tags. STAT3 protein level in both MLS_Stat3_NES clones is lower than Stat3 ${ }^{+/+}$cells. B: qPCR analysis of the Stat3 and its nuclear target gene Socs3. Gene expression analysis of Stat3 ${ }^{+/+}$cells, 
Stat3 ${ }^{-/}$cells, and two MLS_Stat3_NES clones (A/B) cultured in presence of LIF. Note that both clones have the same undetectable level of Socs3 as Stat3 ${ }^{-/}$cells. C: Representative confocal images of Stat $^{+/+}$, Stat3 $^{-/}$and MLS_Stat3_NES cells stained with anti-STAT3 and anti-ATAD3 antibodies. Merge image shows co-localization between STAT3 and the nucleoids marked by ATAD3; DAPI serves as a nuclear counterstain. Scale bar: $20 \mu \mathrm{m}$.

Fig S2: Validation of the injected mRNAs on zebrafish. A: IF on zebrafish cells, dissociated and plated from 24-hpf embryos injected with mStat3 and MLS_mStat3 mRNA. The antibody reveals the expression of mSTAT3 (green). The mito-targeted STAT3 co-localizes with ATAD3 (red), a marker of mitochondrial nucleoids, confirming the correct subcellular localization of the proteins. Conversely the analysis of cells from embryos injected with mStat3 mRNA results in a more diffused staining. Scale bar = 10um. B: Whole mount IF on 24-hpf zebrafish embryos injected with pCS2 + MLS_mSTAT3_NES plasmid. The mosaic expression is driven by a CMV promoter to verify the intracellular localization of the murine protein. mSTAT3 (green) staining confirms the expected mitochondrial localization of the protein.

\section{Fig S3: Validation of effects of $m$ Stat3 and MLS_Stat3_NES mRNA injected in} zebrafish embryos A: qRT-PCR analysis of socs3a mRNA levels in 48-hpf embryos injected with $m S$ tat3 and MLS_mStat3_NES. B: qRT-PCR analysis of $m$ t_nd2 mRNA levels in mStat3 and MLS_mStat3_NES 48-hpf injected embryos. C: qRT-PCR analysis of $m t$ nd2 levels from $3.7 \mathrm{hpf}$ to $6 \mathrm{dpf}$, in larvae injected with mStat3 mRNA. D: qRT-PCR analysis of $m S t a t 3$ levels from $3.7 \mathrm{hpf}$ to $6 \mathrm{dpf}$, in larvae injected with mStat3 mRNA. Statistical analysis was performed by unpaired t-test on 3 independent biological samples (where $n$ not specified). ${ }^{*} \mathrm{p}<0.05 ;{ }^{* * *} \mathrm{p}<0.001$; error bars $=\mathrm{SEM}$. 
Fig. S4: STAT3-dependent mitochondrial transcription depends on Y705 and S727 phosphorylations. A: WISH with anti-mt_nd2 mRNA probe in 48-hpf uninjected embryos and embryos injected with either mStat3, mStat3-Y705F or mStat3-S727A. B: WISH with anti- $m t$ nd2 mRNA probe in 48-hpf uninjected embryos and embryos injected with either MLS_mStat3_NES, MLS_mStat3_NES Y705F or MLS_mStat3_NES S727A.

Fig. S5: PD98059 inhibits 5727 phosphorylation of STAT3 in NIH-3T3 cells. A-A': western blot analysis of pSTAT3 S727 in NIH-3T3 cells treated for 24 hours with $12.5 \mu \mathrm{M}$ PD98059 ( $\beta$-Actin was used as a loading control). Statistical analysis was performed by unpaired t-test on 3 independent biological samples. ${ }^{*} \mathrm{p}<0.05$; error bars $=\mathrm{SEM}$.

Fig. S6: $m$ t_nd2 mRNA expression is not affected by AG-490 nor in 48-hpf stat3 mutant larvae. A-A': FISH with $m t$ nd2 probe in the TeO of 48-hpf larvae treated for 24 hours with AG490. Fluorescence quantification of $m t \_n d 2 \mathrm{mRNA}$ levels in the TeO $(\mathrm{n}=10)$. B: FISH with $m t \_n d 2$ probe in the TeO of 48 -hpf $s t a t 3^{+/+}$, stat ${ }^{+/-}$, and stat3 $^{-/-}$larvae. B': fluorescence quantification of $m t$ nd2 mRNA levels in the TeO. Statistical analysis was performed by unpaired t-test on 3 independent biological samples. ns = not significant; error bars=SEM.

Fig. S7: Stat3 depletion does not affect mitochondria morphology and biogenesis in the brain and intestine of stat ${ }^{-/}$larvae. A: TEM analysis of mitochondrial morphology in intestine and brain of 6-dpf stat $3^{-/}$mutants and WT siblings. B: EGFP expression in the intestine of 6-dpf stat3\% $\%$ Tg(CoxVIII-m/s:EGFP) and WT/Tg(CoxVIII-m/s:EGFP) siblings $(n=6)$. C: Fluorescence quantification of EGFP expression in the intestine of 6-dpf stat3 $^{-/}$ ITg(CoxVIII-m/s:EGFP) and WT/Tg(CoxVIII-m/s:EGFP) siblings (p-value=0.,6878).

Statistical analysis was performed by unpaired t-test on indicated number of samples; $\mathrm{ns}=$ not significant; error bars=SEM.

Table 1: List of sgRNAs and primers used for genotyping (5'-3' sequences)

Table 2: List of cloning-related primers (5'-3' sequences)

Table 3: List of qRT-PCR and RT-PCR primers (5'-3' sequences) 
bioRxiv preprint doi: https://doi.org/10.1101/2020.07.17.208264; this version posted January 27, 2021. The copyright holder for this preprint (which was not certified by peer review) is the author/funder, who has granted bioRxiv a license to display the preprint in perpetuity. It is made available under aCC-BY-NC-ND 4.0 International license. 
Fig. 1

bioRxiv preprint doi: https://doi.org/10.1101/2020.07.17.208264; this version posted January 27, 2021. The copyright holder for this preprint (which was not certified by peer review) is the author/funder, who has granted bioRxiv a license to display the preprint in perpetuity. It is made available under aCC-BY-NC-ND 4.0 International license.

pcna mt_nd2 stat3
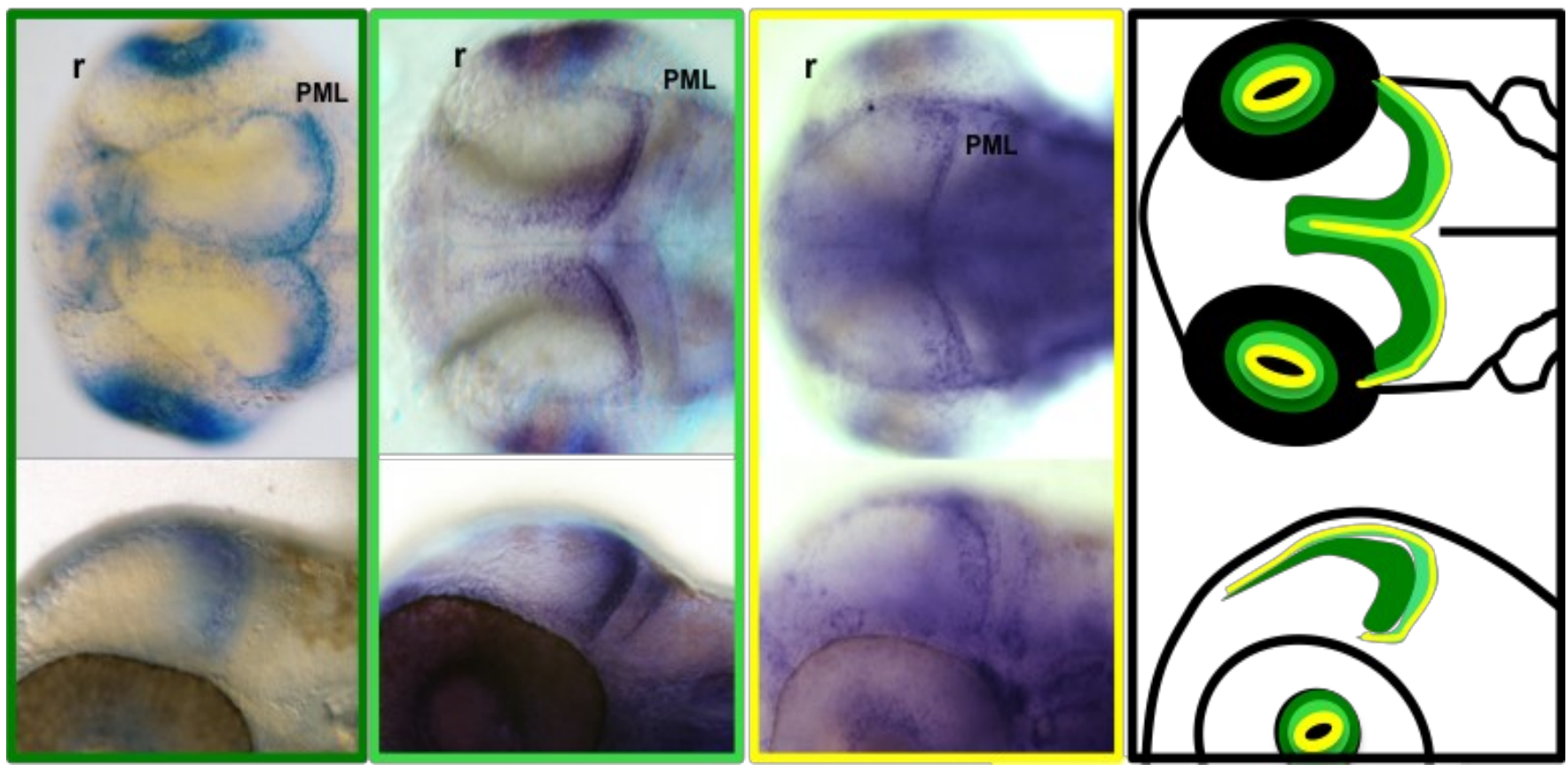

Fig. 1: Stat3 mRNA is co-expressed with proliferation and mtDNA transcription markers in the $\mathrm{TeO}$ of zebrafish embryos. Whole mount in situ hybridization (WISH) on 48-hpf zebrafish WT embryos using pcna (dark green frame and outline), $m$ t_nd2 (light green frame and outline), and stat3 (yellow frame and outline) antisense mRNA probes shows co expression of the three transcripts in the PML region of the $\mathrm{TeO}$; $r=$ retina; $P M L=$ Peripheral Midbrain Layer. 
Fig. 2

bioRxiv preprint doi: https://doi.org/10.1101/2020.07.17.208264; this version posted January 27, 2021. The copyright holder for this preprint (which was not certified by peer review) is the author/funder, who has granted bioRxiv a license to display the preprint in perpetuity. It is made available under aCC-BY-NC-ND 4.0 International license.

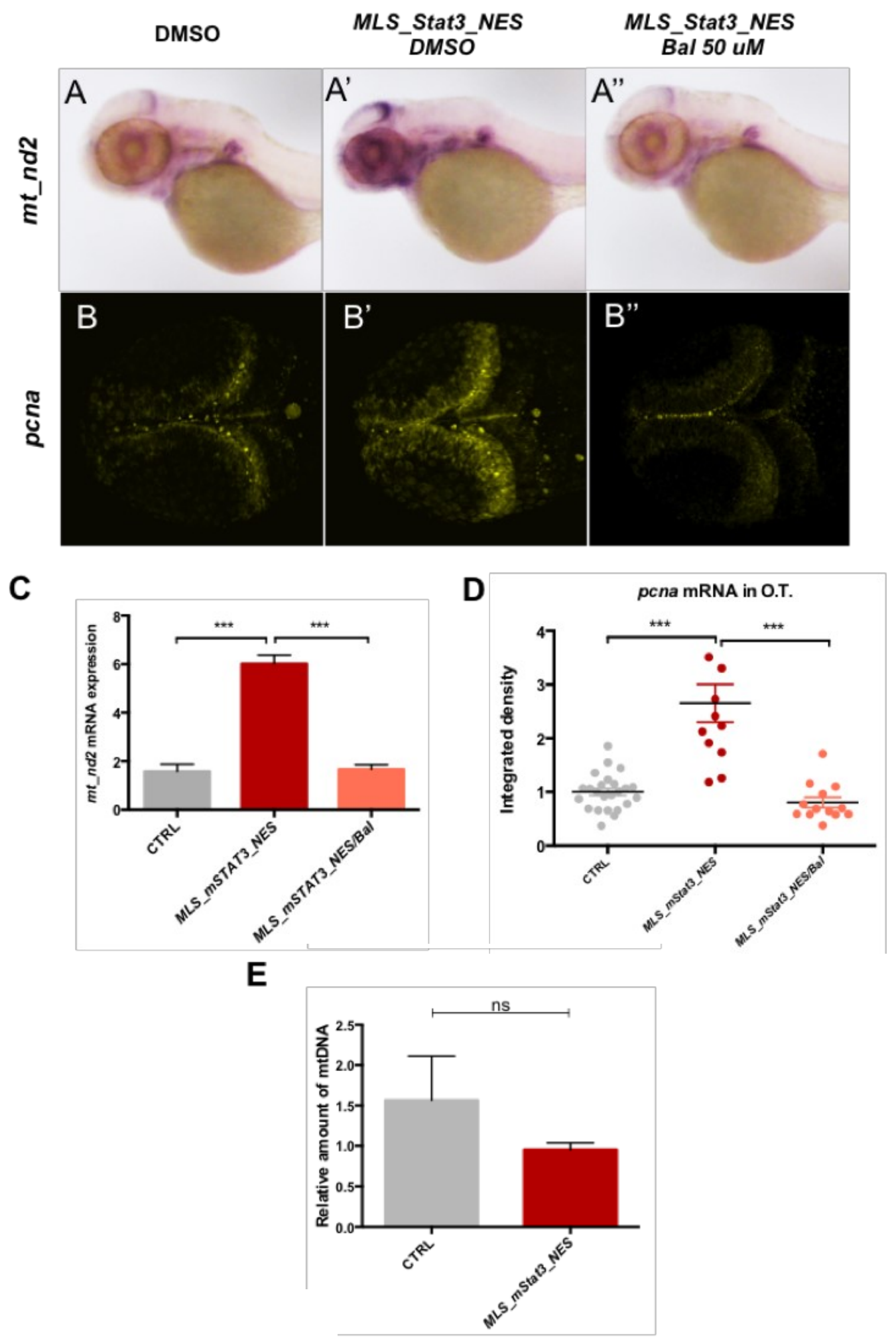




\section{Fig. 2: mitoSTAT3 regulates proliferation through mitochondrial DNA}

transcription. A-A": WISH with anti-mt_nd2 mRNA probe representing mitochondrial gene transcription in: uninjected embryos (A); embryos injected with MLS_mStat3_NES mRNA (A'); MLS_mStat3_NES mRNA injected embryos treated with $50 \mu \mathrm{M}$ Balapiravir (A"). B-B": Fluorescent in situ hybridization (FISH) with pcna probe in the $\mathrm{TeO}$ of: uninjected embryos (B); embryos injected with MLS_mStat3_NES mRNA (B'); and injected embryos treated with $50 \mu \mathrm{M}$ Balapiravir (B"). C: qRT-PCR showing $m t \_n d 2$ gene expression after injection of MLS_mStat3_NES mRNA and treatment with Balapiravir at 48 hours post injection (hpi); zgapdh was used as internal control ( $p$ values $=0.0007 ; 0.0005)$. D: Fluorescence quantification of $p c n a$ mRNA expression in the $\mathrm{TeO}(n=12)$ ( $p$-values $=<0.0001 ; 0.0108 ; 0.0122)$. E: Relative amount of mtDNA in embryos injected with MLS_mStat3_NES mRNA and uninjected controls at $48 \mathrm{hpf}$. Mean $\mathrm{dCt}$ values were calculated as $\mathrm{Ct}$ of $m t$ _nd1 (mitochondrial encoded gene) minus Ct of polg1 (nuclear encoded gene) ( $p$-value $=0.3295)$. Statistical analysis was performed by unpaired t-test on 3 independent biological samples (where $\mathrm{n}$ not specified). ns: not significant; ${ }^{*} p<0.05$; ${ }^{* *} p<0.01$; ${ }^{* * *} p<0.001$; error bars $=S E M$. 
Fig. 3

bioRxiv preprint doi: https://doi.org/10.1101/2020.07.17.208264; this version posted January 27, 2021. The copyright holder for this preprint (which was not certified by peer review) is the author/funder, who has granted bioRxiv a license to display the preprint in perpetuity. It is made available under aCC-BY-NC-ND 4.0 International license.
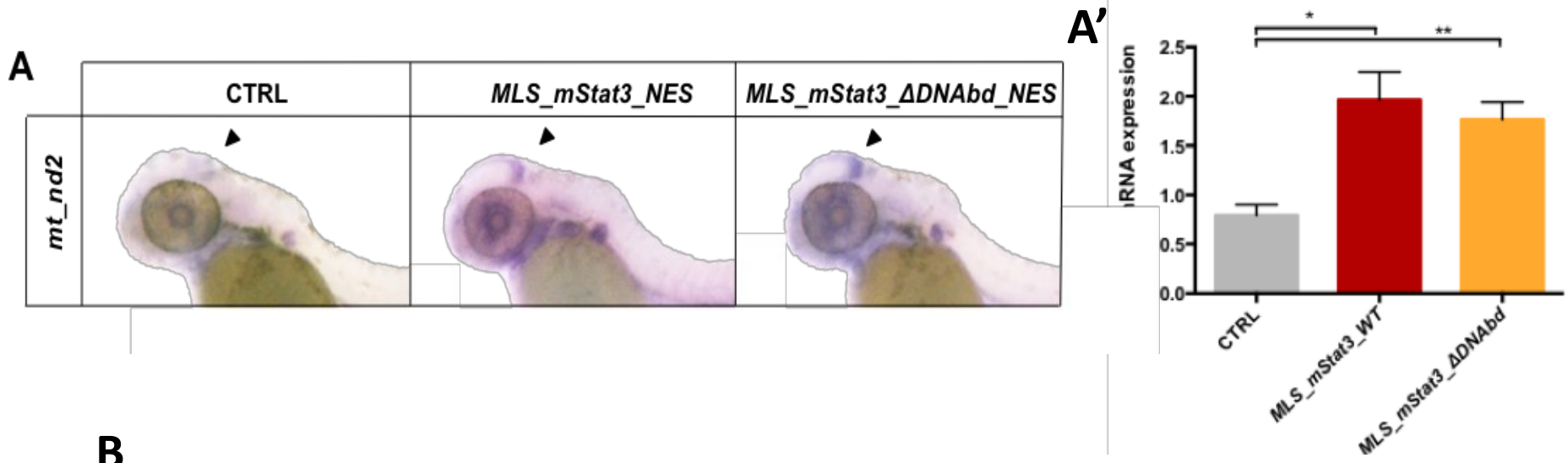

B
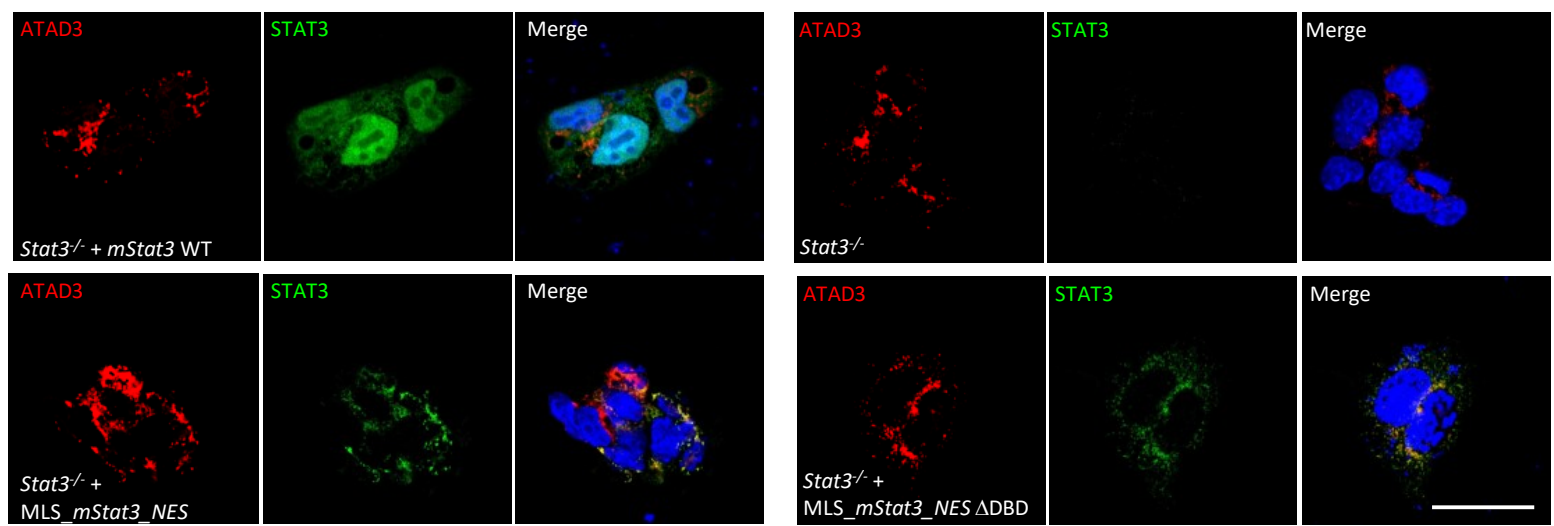

Fig. 3: Mutation of Stat3 DBD of does not affect its mitochondrial activities. A-A': qRTPCR showing $m t \_n d 2$ gene expression after injection of $M L S \_m S t a t 3 \_N E S$ or MLS_mStat3_DDNAbd_NES mRNA in 48-hpf embryos; zgapdh was used as internal control (p-values $=0.0184 ; 0.0093)$. B: immunofluorescence on ESCs transiently transfected with MLS_mStat3_NES or MLS_mStat3_ADNAbd_NES and stained with anti-STAT3 (green), antiATAD3 (red) Ab and DAPI (blue). Scale bar: $200 \mu \mathrm{m}$. Statistical analysis in C-F was performed by unpaired t-test on 3 independent biological samples (where $n$ not specified). ns: not significant; ${ }^{*} p<0.05 ;{ }^{* *} p<0.01$; error bars $=S E M$. 
Fig. 4

bioRxiv preprint doi: https://doi.org/10.1101/2020.07.17.208264; this version posted January 27, 2021. The copyright holder for this preprint (which was not certified by peer review) is the author/funder, who has granted bioRxiv a license to display the preprint in perpetuity. It is made

A

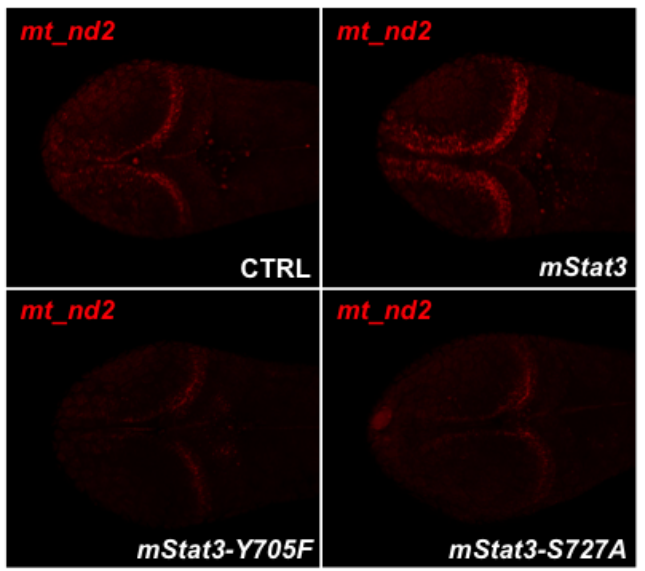

C

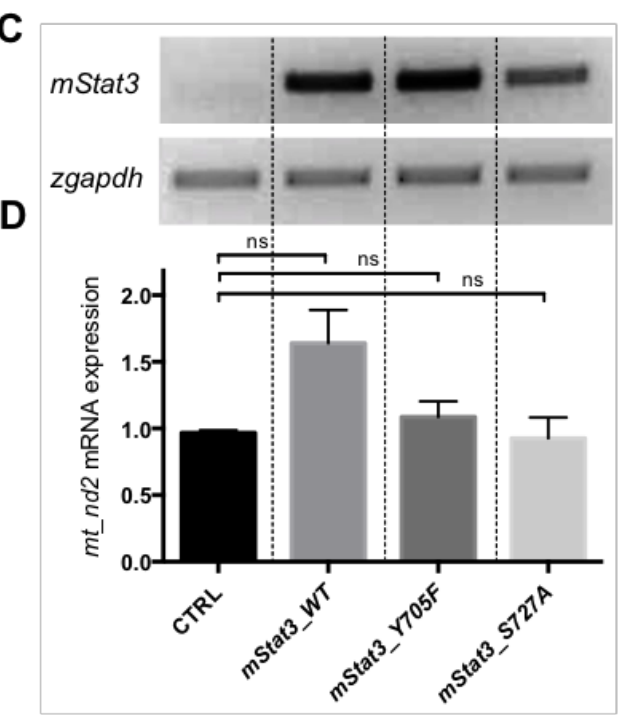

B

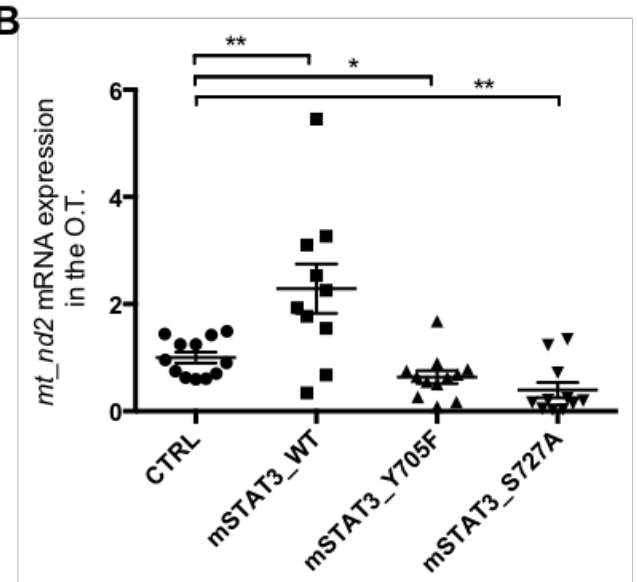

E

E $m$ Stat3

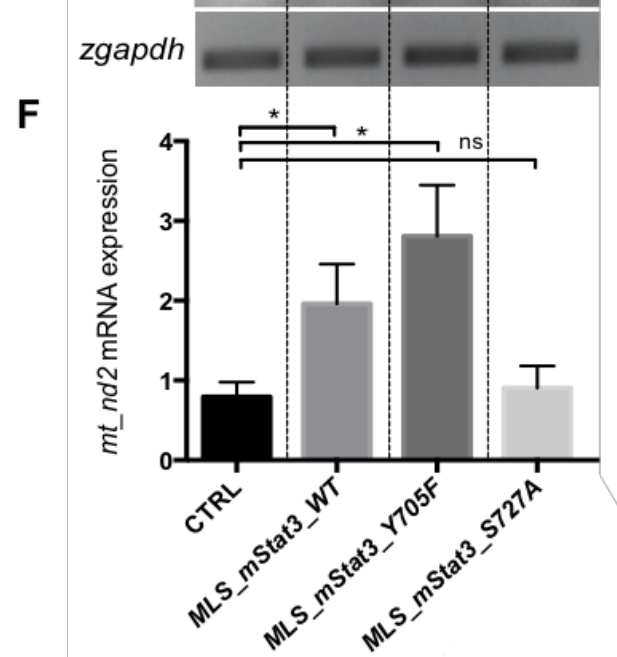

\section{Fig. 4: mitoSTAT3 transcriptional activity relies on both S727 and Y705}

phosphorylations. A: FISH with $m t$ nd2 probe in the TeO of 48-hpf embryos injected with mRNA encoding the indicated isoforms of $m S t a t 3$. B: Fluorescence quantification of $m t \_n d 2$ mRNA expression in the TeO $(n=10)$ (p-values $=0.0074 ; 0.0307 ; 0.0023)$. C: RT-PCR analysis of $m$ Stat 3 transcripts detected at $48 \mathrm{hpf} / \mathrm{hpi}$ in embryos injected with the indicated form of $m$ Stat3 mRNA; zgapdh was used as internal control. D: qRT-PCR analysis of $m t$ nd 2 transcript levels at $48 \mathrm{hpf} / \mathrm{hpi}$ normalized to zgapdh ( $\mathrm{p}$ values $=0.0888 ; 0.1899 ; 0.8334$ ). E: RT-PCR analysis of MLS_mStat3_NES transcripts detected at $48 \mathrm{hpf} / \mathrm{hpi}$ in embryos injected with indicated form of mitochondria-targeted $m S t a t 3 \mathrm{mRNA}$; zgapd $h$ was used as internal control. F: qRT-PCR analysis of $m t \_n d 2$ transcript levels at $48 \mathrm{hpf} / \mathrm{hpi}$ normalized to zgapdh ( $\mathrm{p}$ values= $0.0184 ; 0.0355 ; 0.5846)$. Statistical analysis was performed by unpaired t-test on 3 independent biological samples (where $n$ not specified). ns: not significant; ${ }^{*} p<0.05$; ${ }^{* *} p<0.01$; error bars $=$ SEM. 
Fig. 5

bioRxiv preprint doi: https://doi.org/10.1101/2020.07.17.208264; this version posted January 27, 2021. The copyright holder for this preprint (which was not certified by peer review) is the author/funder, who has granted bioRxiv a license to display the preprint in perpetuity. It is made available under aCC-BY-NC-ND 4.0 International license.

A
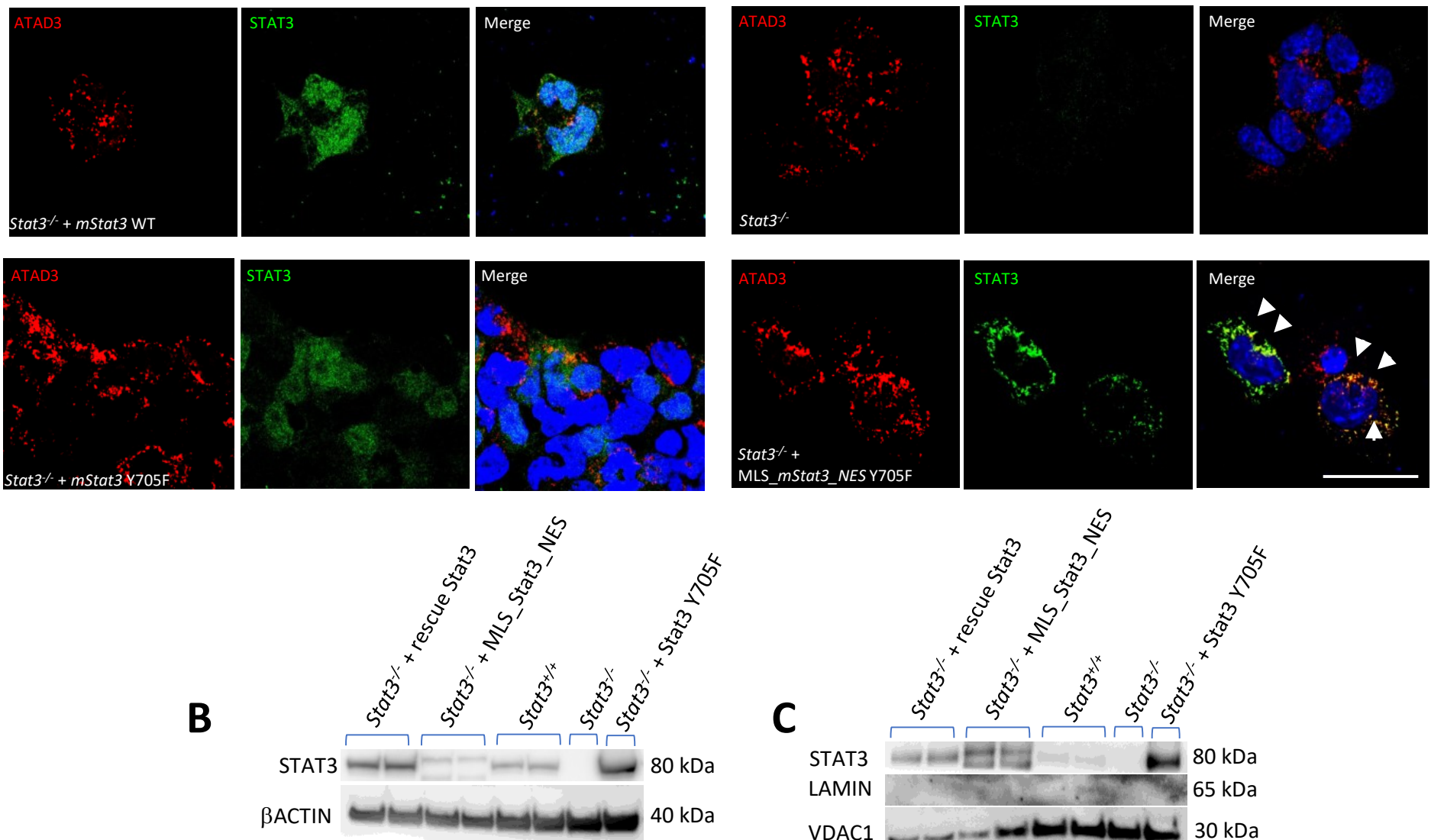

D

Total extracts

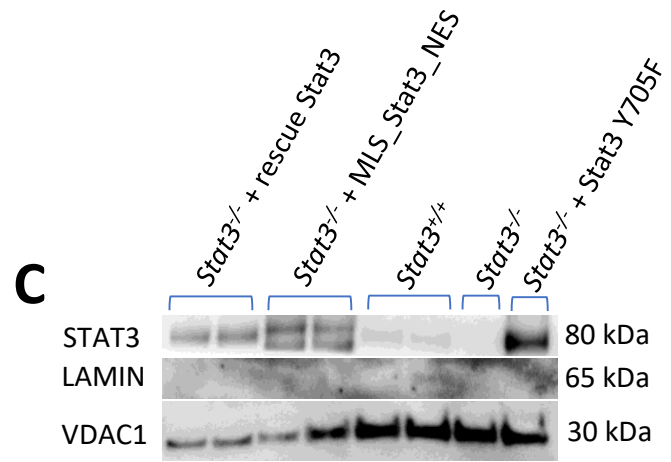

Mitochondrial extracts

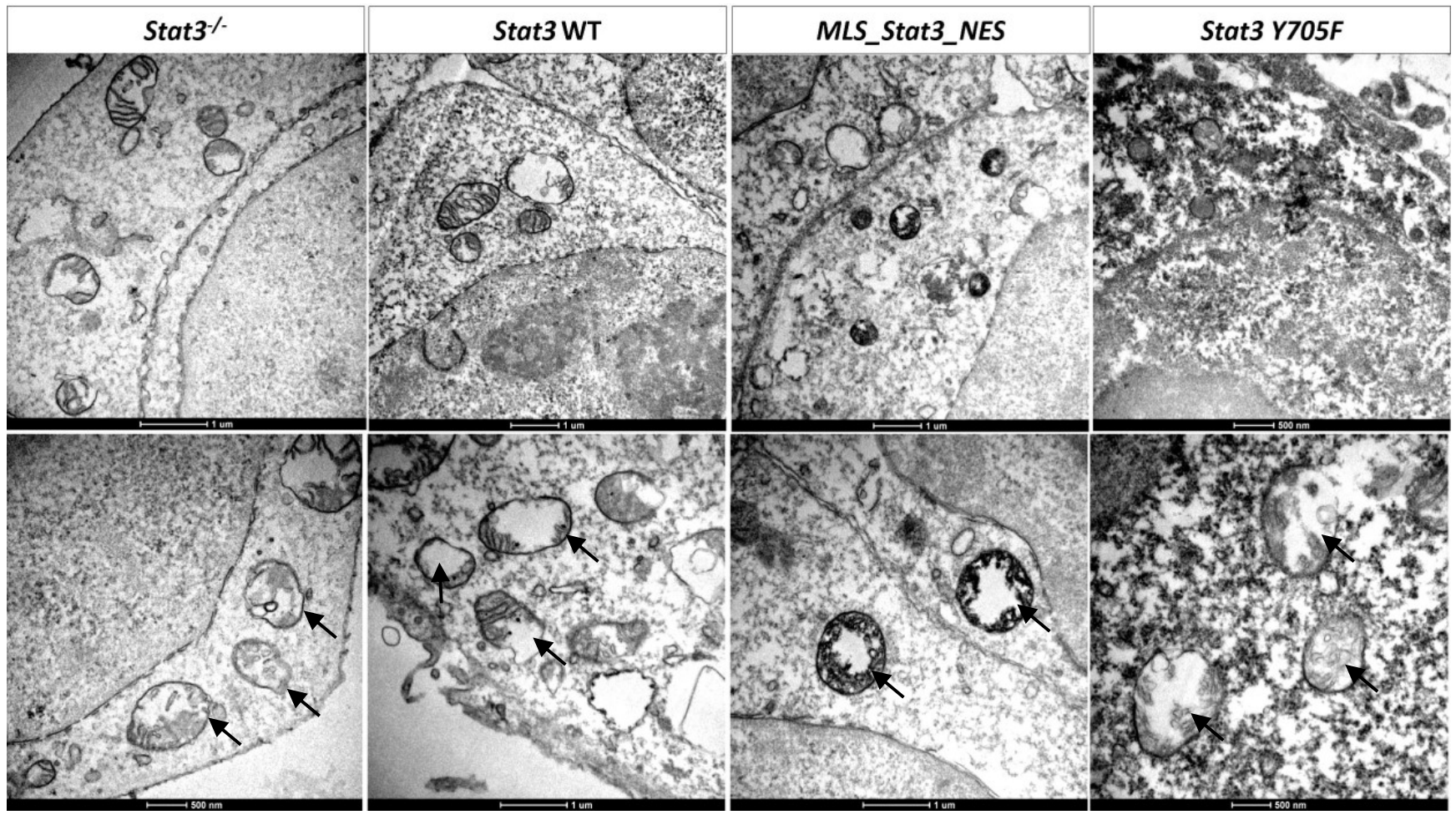


Fig. 5: Y705 phosphorylation is needed for the correct localization of STAT3 in the mitochondrion. A: immunofluorescence with anti-STAT3 and anti-ATAD3 Ab on ESCs transient transfected with either mStat3, mStat3 Y705F or MLS_mStat3_NES Y705F. Arrows indicate the colocalization of ATAD and STAT3. Scale bar: $200 \mu \mathrm{m}$. B: western blot of total STAT3 in ESCs extracts, $\beta$-actin was used as a loading control. C: western blot of mitochondrial STAT3 from ESCs mitochondrial extracts; VDAC1 was used as a mitochondrial loading control, Lamin was used as a control for nuclear contamination. D: representative pictures of DAB immunohistochemistry on ESCs acquired with TEM; positive signal is black and negative is white. Arrows indicate mitochondria. Cristae are positive in Stat3 WT and MLS_Stat3_NES transfected cells. 
Fig. 6

bioRxiv preprint doi: https://doi.org/10.1101/2020.07.17.208264; this version posted January 27, 2021. The copyright holder for this preprint (which was not certified by peer review) is the author/funder, who has granted bioRxiv a license to display the preprint in perpetuity. It is made available under aCC-BY-NC-ND 4.0 International license.

A

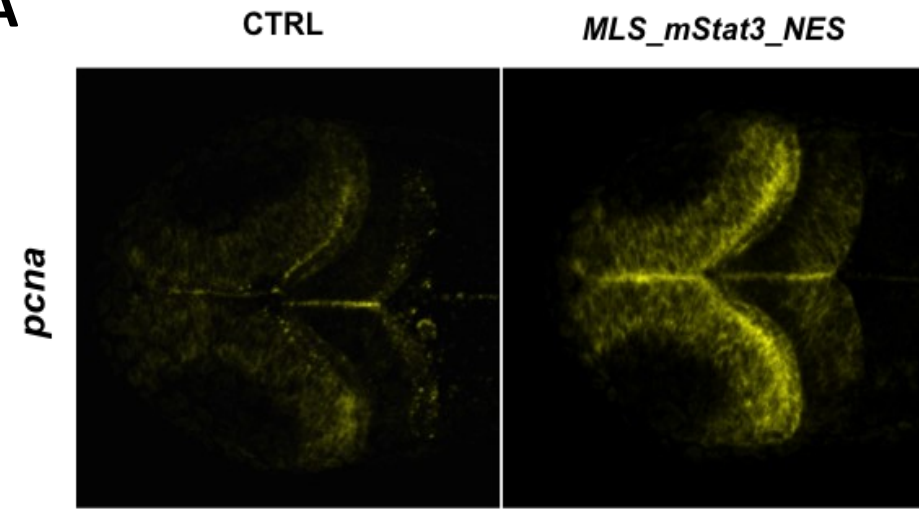

B
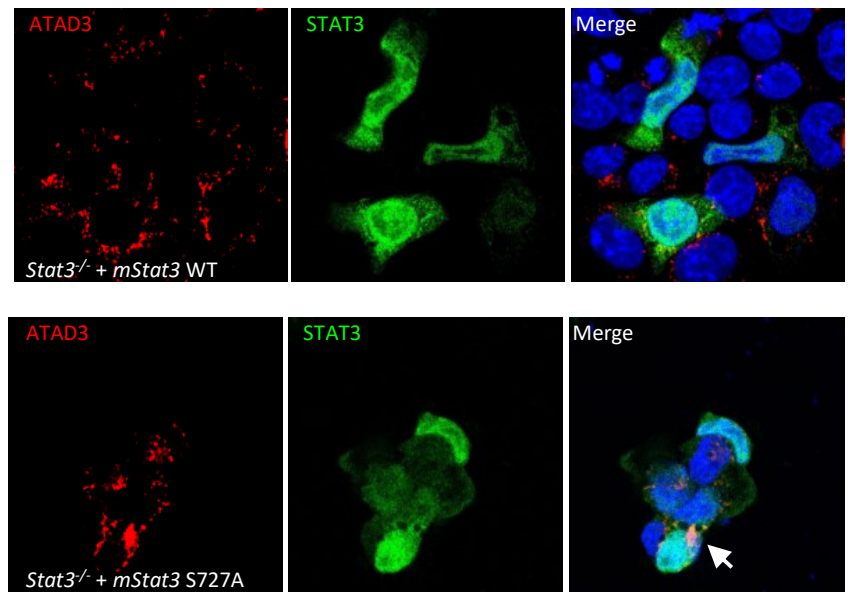

MLS_mStat3_NES_S727A

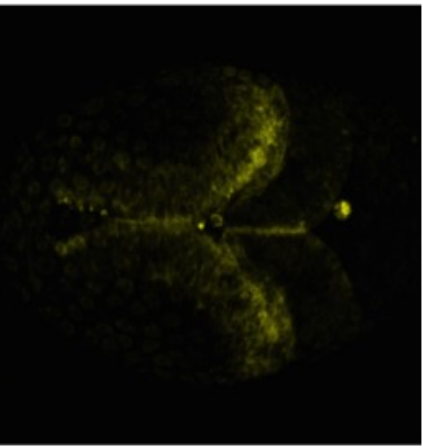

$A^{\prime}$
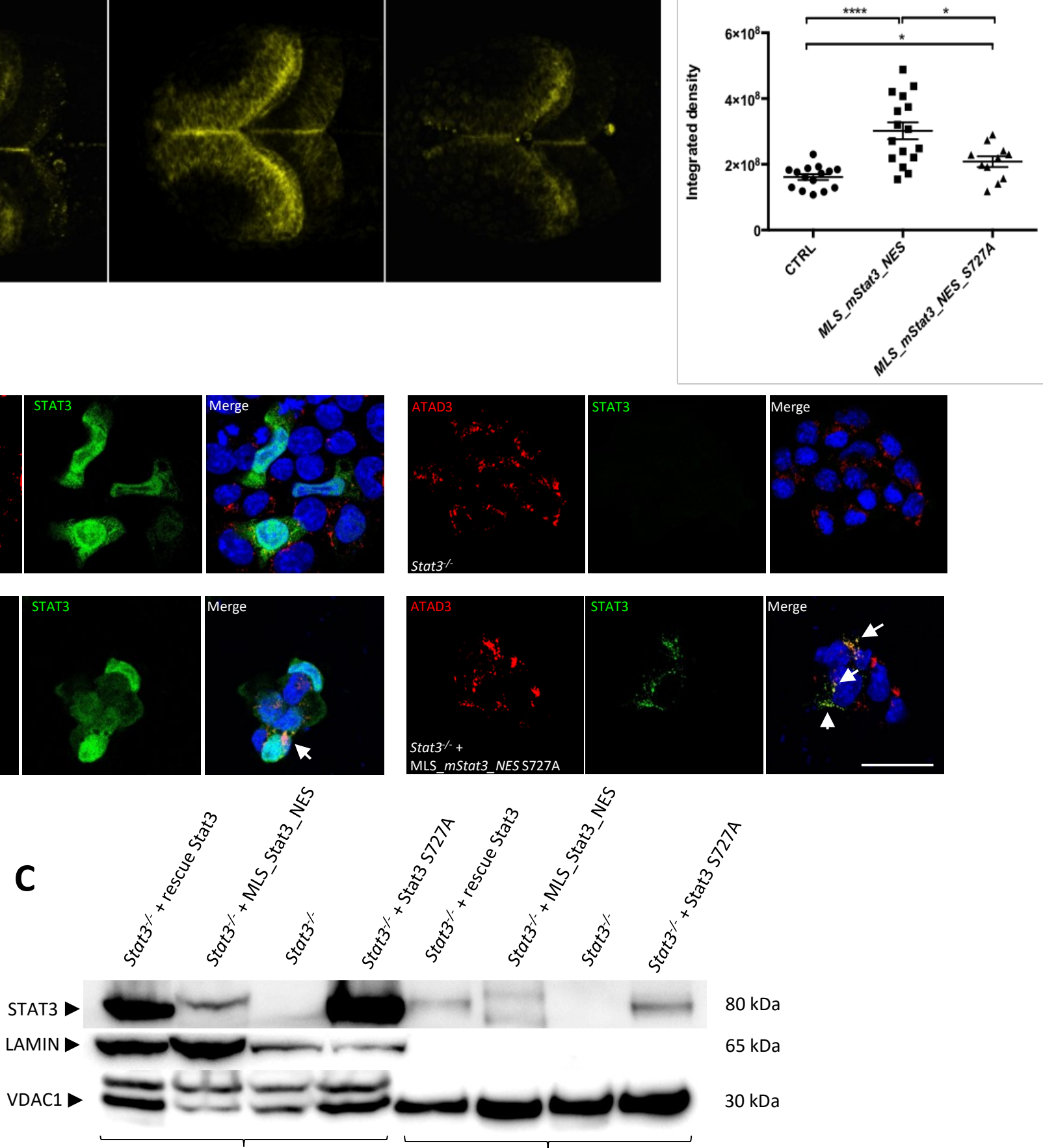

Total extracts

Mitochondrial extracts

D

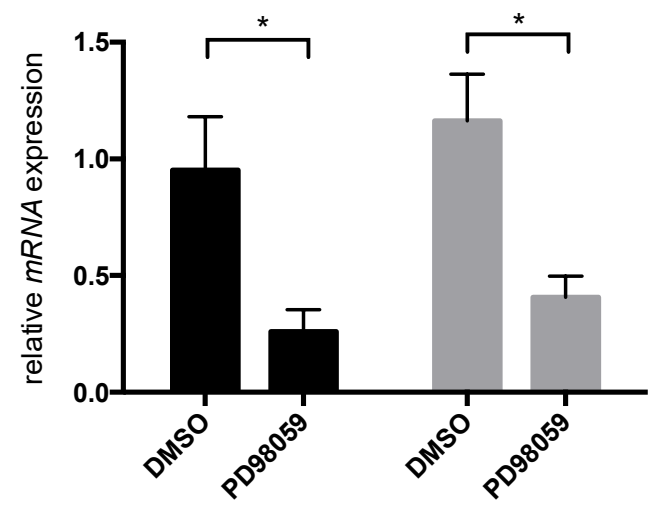

$m t-n d 2$

pcna 
Fig. 6: mitoSTAT3-dependent activation of cell proliferation in the TeO depends on S727 phosphorylation. A-A': Representative pictures of WISH performed with an anti-pcna probe on 48-hpf uninjected larvae, larvae injected with MLS_mStat3_NES and MLS_mStat3_NES S727A mRNAs (A). Fluorescence quantification of pcna mRNA expression in the $\mathrm{TeO}(n=12)$ (p-values $=<0.0001 ; 0.0108 ; 0.0122)\left(\mathbf{A}^{\prime}\right)$. B: immunofluorescence with anti-STAT3 and anti-ATAD3 Ab on ESCs Stat3 -/- transiently transfected with the constructs encoding: $m S t a t 3, M L S \_m S t a t 3 \_N E S$, MLS_mStat3_NES S727A or mStat3. Arrows indicate the colocalization of ATAD and STAT3. Scale bar: $200 \mu \mathrm{m}$. C: western blot of mitochondrial STAT3 from ESCs mitochondrial extracts; VDAC1 was used as a mitochondrial loading control, Lamin was used as a nuclear loading control. D: qRT-PCR analysis of $m t \_n d 2$ and pcna on 48-hpf larvae treated with either PD98059 12.5 $\mu \mathrm{M}$ or DMSO. Statistical analysis was performed by unpaired t-test on 3 independent biological samples (where $\mathrm{n}$ not specified). ${ }^{*} p<0.05 ;{ }^{* * * *} p<0.0001$; error bars $=S E M$. 
bioRxiv preprint doi: https://doi.org/10.1101/2020.07.17.208264; this version posted January 27, 2021. The copyright holder for this preprint (which was not certified by peer review) is the author/funder, who has granted bioRxiv a license to display the preprint in perpetuity. It is made available under aCC-BY-NC-ND 4.0 International license.

A

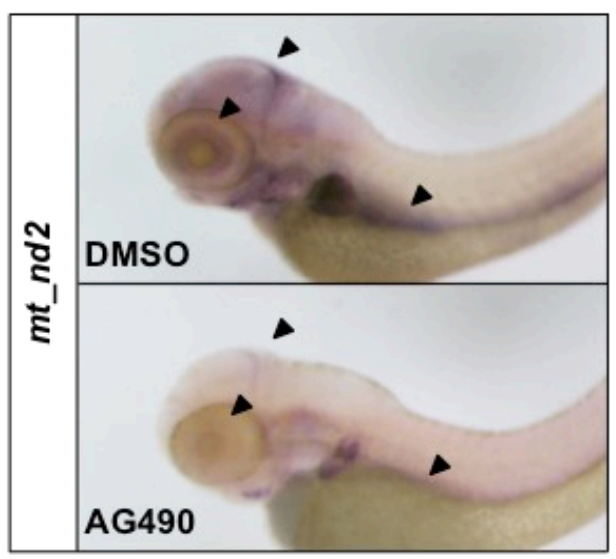

C

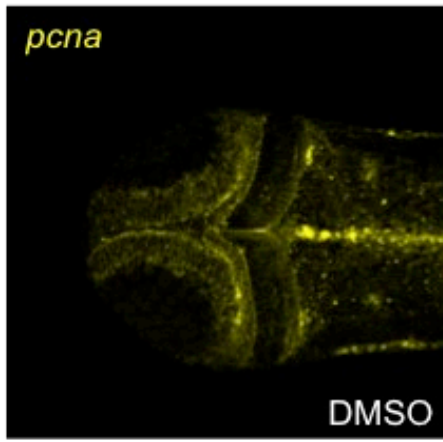

B

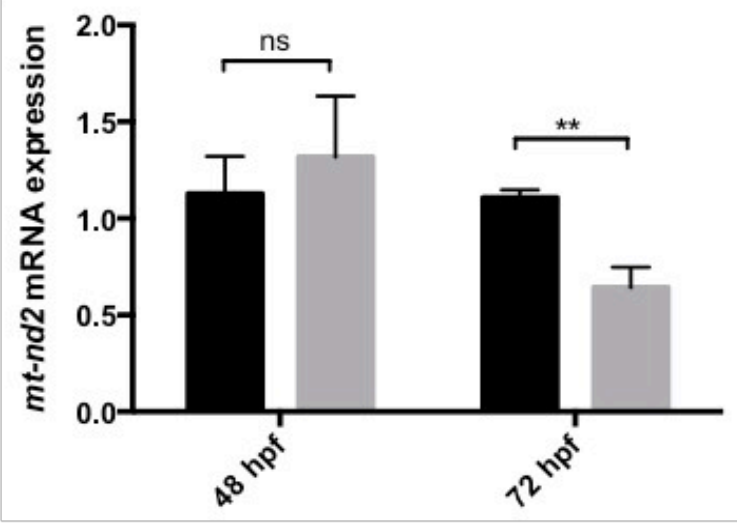

D pcna mRNA in O.T.
CTRL

AG490 100uM

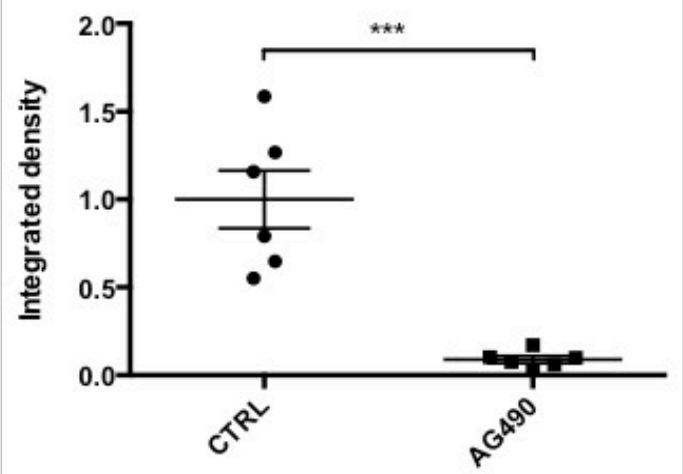

Fig. 7: JAK inhibition impairs normal mitochondrial transcription and cell proliferation in the TeO of 72-hpf embryos. A: WISH with anti-mt_nd2 mRNA probe on 72-hpf embryos treated with $100 \mu \mathrm{M}$ AG490 from 24-72 hpf and DMSO treated controls. B: relative $m t \_n d 2$ transcript expression assayed by qRT-PCR in 48- and 72-hpf embryos treated with $100 \mu \mathrm{M}$ AG490 and DMSO treated controls starting from $24 \mathrm{hpf}$; zgapdh was used as internal control (p-values $=0.6261 ; 0.0060$ ). C: FISH with anti-pcna probe in the TeO of 72-hpf embryos treated with $100 \mu \mathrm{M}$ AG490 from 24 to $72 \mathrm{hpf}$ and DMSO treated controls. D: Fluorescence quantification of pcna mRNA expression in the TeO $(n=6)(p$ value $=0.0003)$. Statistical analysis was performed by unpaired t-test on 3 independent biological samples (where $\mathrm{n}$ not specified). ns: not significant; ${ }^{* *} p<0,01 ;{ }^{* * *} p<0.001$; error bars $=$ SEM. 
bioRxiv preprint doi: https://doi.org/10.1101/2020.07.17.208264; this version posted January 27, 2021. The copyright holder for this preprint (which was not certified by peer review) is the author/funder, who has granted bioRxiv a license to display the preprint in perpetuity. It is made available under aCC-BY-NC-ND 4.0 International license.

A

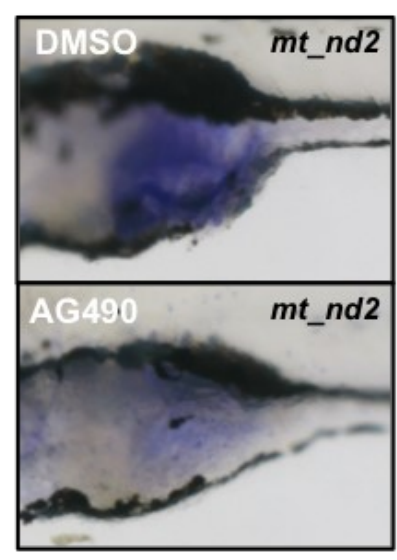

B

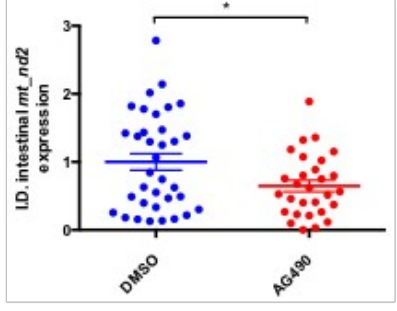

C

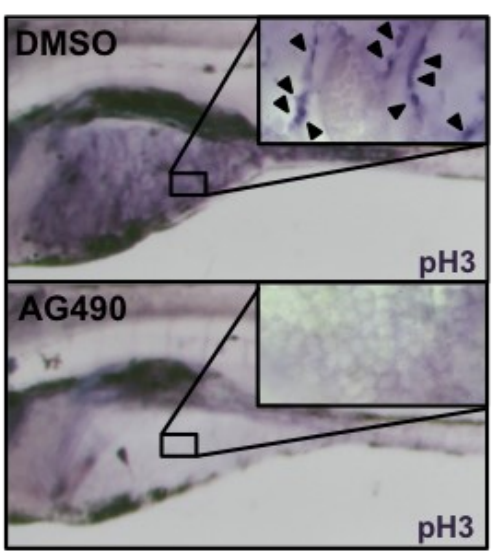

D

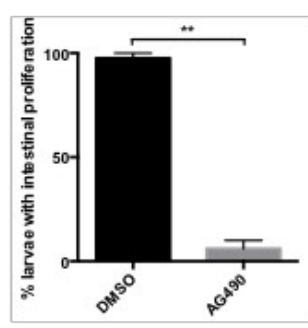

E

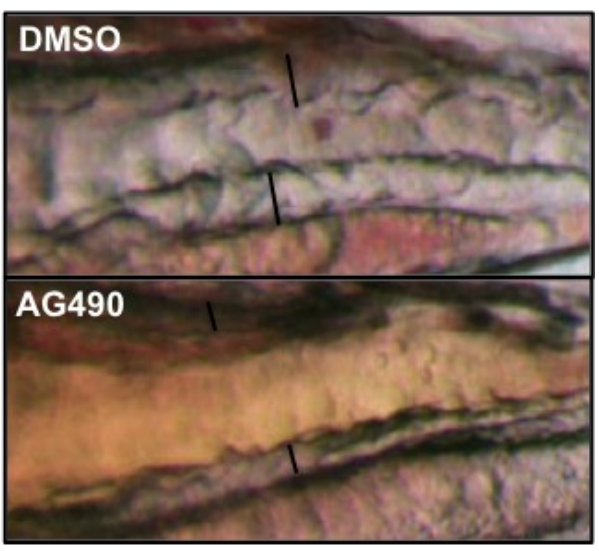

$\mathbf{F}$

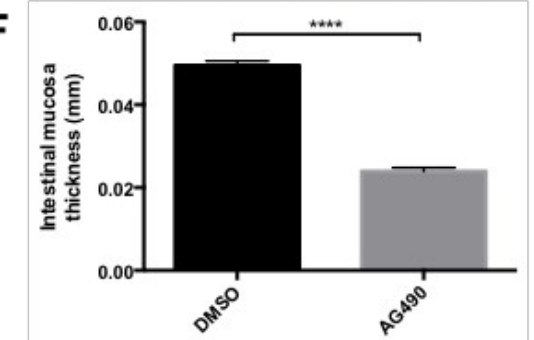

Fig. 8: JAK inhibition impairs normal mitochondrial transcription and cell proliferation in the intestine of 6-dpf larvae. A: WISH with anti-mt_nd2 mRNA probe on 6-dpf larvae treated with $60 \mu \mathrm{M}$ AG490 from 24-72 hpf and DMSO treated controls; zoom on the intestine. B: Quantification of $m t n d 2$ mRNA expression in the intestine $(n=30)(p$-value= 0.0240$)$. C: phospho-Histone- $-\mathrm{H} 3(\mathrm{pH} 3)$ immunostaining of 6 -dpf AG490 treated larvae and DMSO treated controls; zoom on the intestine; ( $\mathrm{pH} 3$ positive cells=arrowheads). D: Quantification of the number of AG490 and DMSO treated larvae displaying intestinal proliferation $(n=15)(p$-value $=0.0026)$. E: AG490 treated larvae showing loss of folding in intestinal mucosa. F: Graph showing the dimension of mucosal thickness in both DMSO and AG490 6-dpf treated larvae $(n=18)(p$-value= $0,0001)$. Statistical analysis was performed by unpaired $t$ test on indicated number of samples; ${ }^{*} p<0.05 ;{ }^{* *} p<0.01 ;{ }^{* * *} p<0.001$; error bars $=$ SEM. 
bioRxiv preprint doi: https://doi.org/10.1101/2020.07.17.208264; this version posted January 27, 2021. The copyright holder for this preprint (which was not certified by peer review) is the author/funder, who has granted bioRxiv a license to display the preprint in perpetuity. It is made available under aCC-BY-NC-ND 4.0 International license.

A
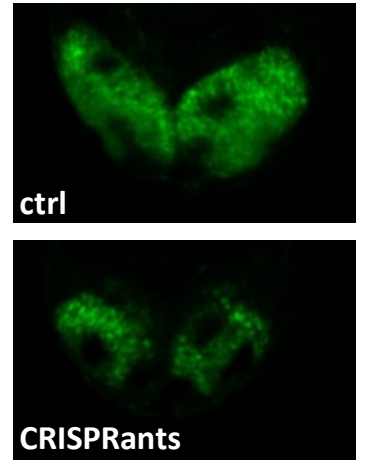

B

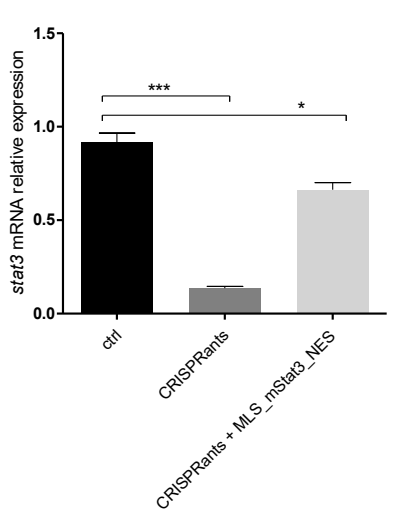

E

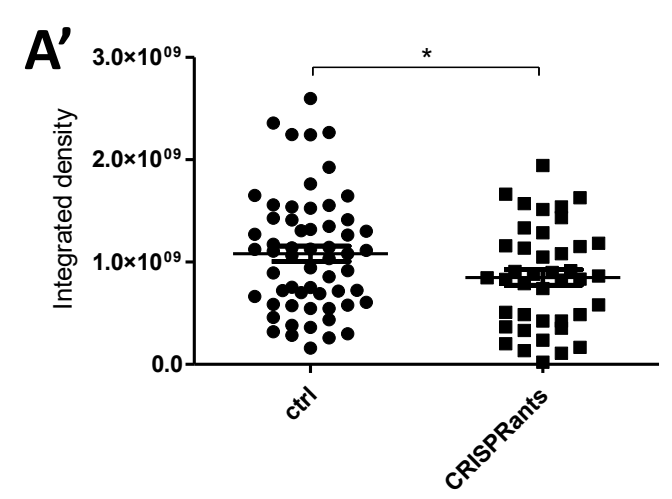

$A^{\prime \prime}$

ex14 ex22 ex23

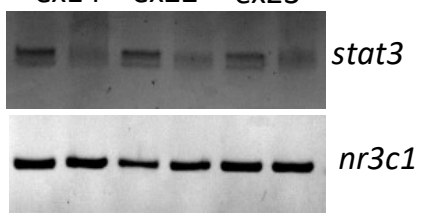

C

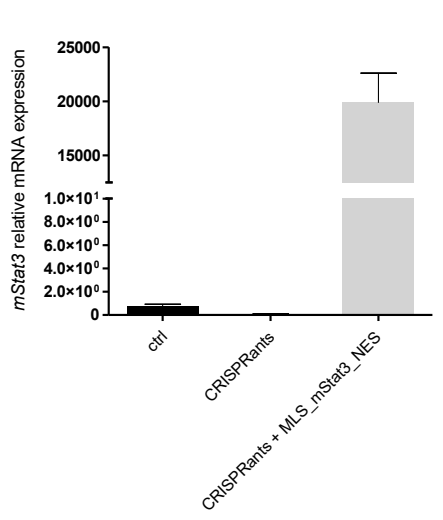

D

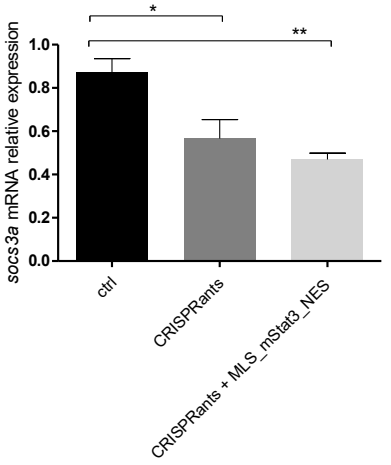

F

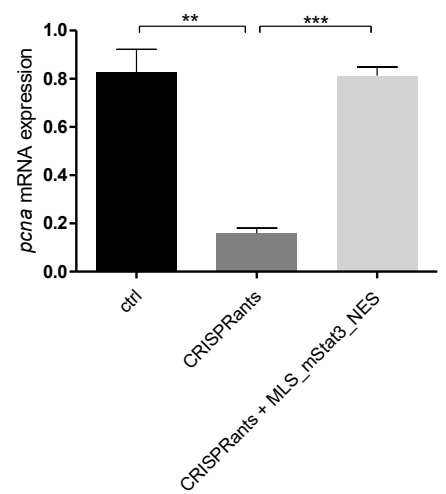

Fig. 9: stat3 CRISPRants show reduced mitochondrial transcription that is rescued by mitochondrial Stat3. A-A": Representative pictures of 48-hpf Tg(7xStat3:EGFP) transgenic zebrafish larvae. Fluorescent quantification of $\mathrm{TeO}$ of control and CRISPRant zebrafish larvae. PCR amplification of the stat3 gene on DNA extracts from control and CRISPRant larvae ( $n r 3 c 1$ gene is used as an internal control). B: qRT-PCR against stat3 in 48-hpf control, CRISPRants and CRISPRants + MLS_mStat3_NES mRNA zebrafish larvae. C: qRT-PCR against Stat3 in 48hpf control, CRISPRants and CRISPRants + MLS_mStat3_NES mRNA zebrafish larvae. D: qRT-PCR against socs3a in 48-hpf control, CRISPRants and CRISPRants+MLS_mStat3_NES mRNA zebrafish larvae. E: qRT-PCR against $m t \_n d 2$ in 48-hpf control, CRISPRants and CRISPRants+MLS_mStat3_NES mRNA zebrafish larvae. F: qRT-PCR against pcna in 48-hpf control, CRISPRants and CRISPRants+MLS_mStat3_NES mRNA zebrafish larvae. Statistical analysis was performed by unpaired t-test on 3 independent biological samples (where $\mathrm{n}$ not specified). ${ }^{*} p<0.05 ;{ }^{* *} p<0.01 ;{ }^{* * *} p<0.001$; error bars $=$ SEM. 
Fig. 10

bioRxiv preprint doi: https://doi.org/10.1101/2020.07.17.208264; this version posted January 27, 2021. The copyright holder for this preprint (which was not certified by peer review) is the author/funder, who has granted bioRxiv a license to display the preprint in perpetuity. It is made available under aCC-BY-NC-ND 4.0 International license.
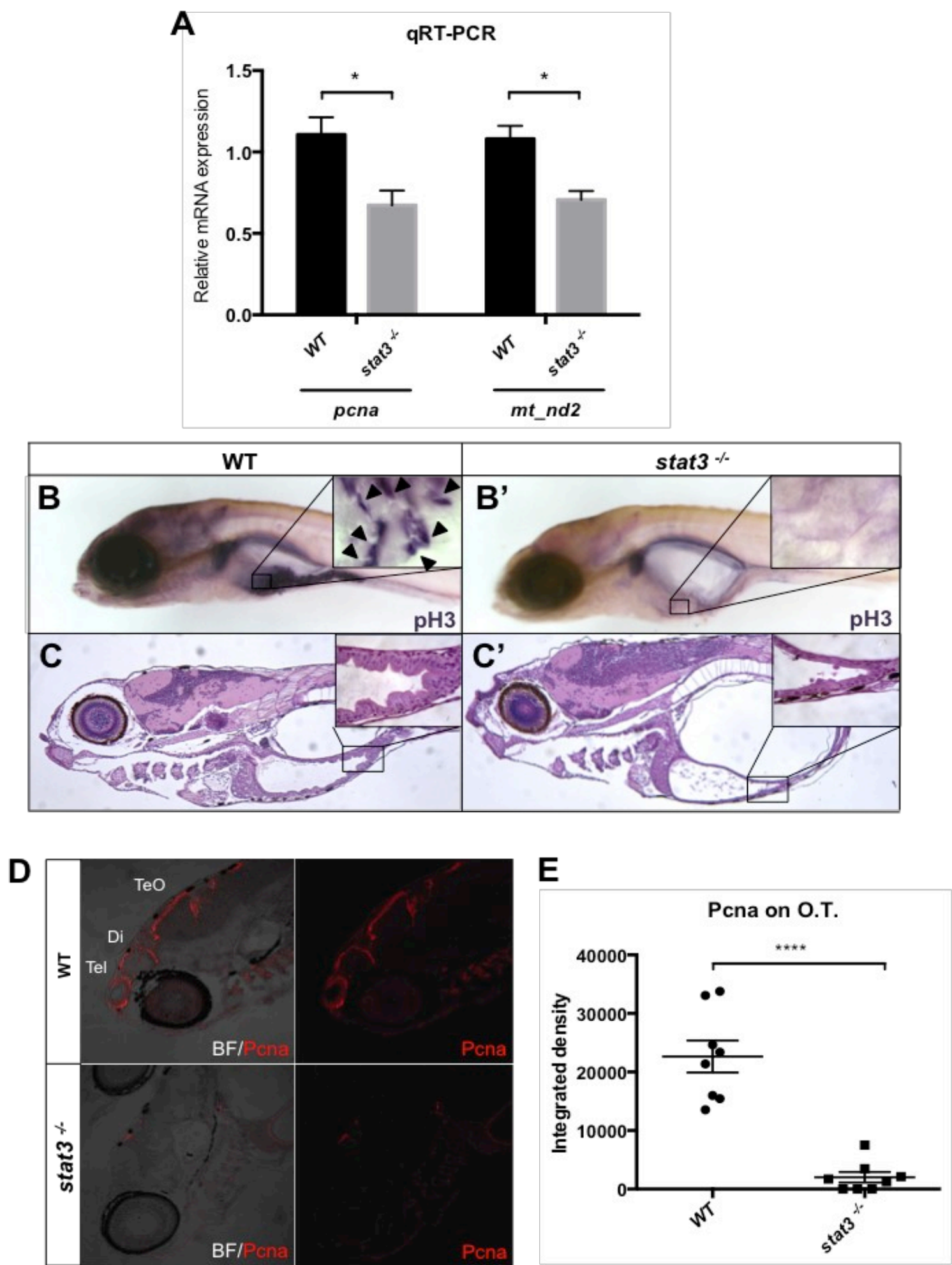
Fig. 10: stat3 KO impairs normal mitochondrial transcription and cell proliferation in the intestine and brain of 6-dpf zebrafish larvae. A: Relative mRNA expression of $m t$ nd 2 and pcna transcripts assayed by qRT-PCR in homogenized stat $3^{-/-}$and WT siblings at $6 \mathrm{dpf} ; \mathrm{zgapdh}$ was used as internal control ( $p$ values=0.0358; 0.0182). B-B': phospho-Histone-H3 $(\mathrm{pH} 3)$ immunostaining of stat $3^{--}$and WT siblings at $6 \mathrm{dpf}$; zoom on the intestine. (pH3 positive cells=arrowheads). C-C': EE staining on WT and stat3 $3^{-/}$ mutant sections at $6 \mathrm{dpf}$ shows the complete loss of folding in the mutant intestinal epithelium. D: IF with anti-PCNA Ab on 6-dpf stat3 ${ }^{-/-}$mutants showing decrease of fluorescence in the CNS (Tel= telencephalon; Di: diencephalon; TeO: tectum opticum). E: Fluorescence quantification of PCNA protein on lateral sections of 6-dpf stat3--/ mutants and WT siblings; zoom on the head $(n=8)(p$-value $<0.0001)$. Statistical analysis was performed by unpaired t-test on 3 independent biological samples (where $\mathrm{n}$ not specified). ${ }^{*} p<0.05 ;{ }^{* * * *} p<0.0001$; error bars $=S E M$. 
Fig. S1

bioRxiv preprint doi: https://doi.org/10.1101/2020.07.17.208264; this version posted January 27, 2021. The copyright holder for this preprint (which was not certified by peer review) is the author/funder, who has granted bioRxiv a license to display the preprint in perpetuity. It is made available under aCC-BY-NC-ND 4.0 International license.

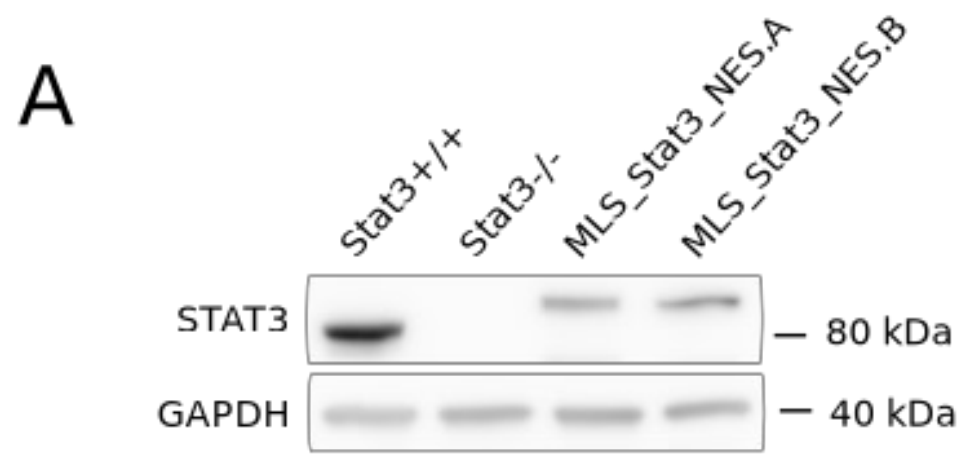

B

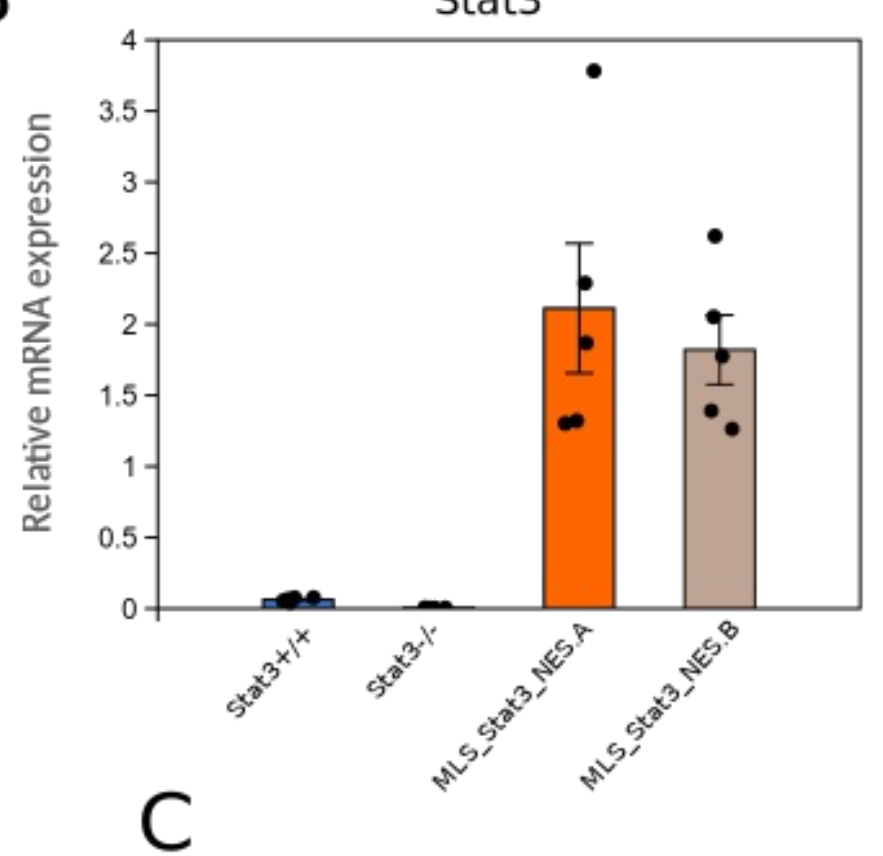

Stat3+/+

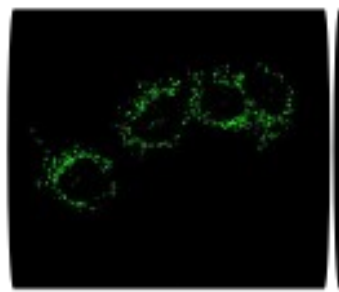

STAT3

Merge with DAPI

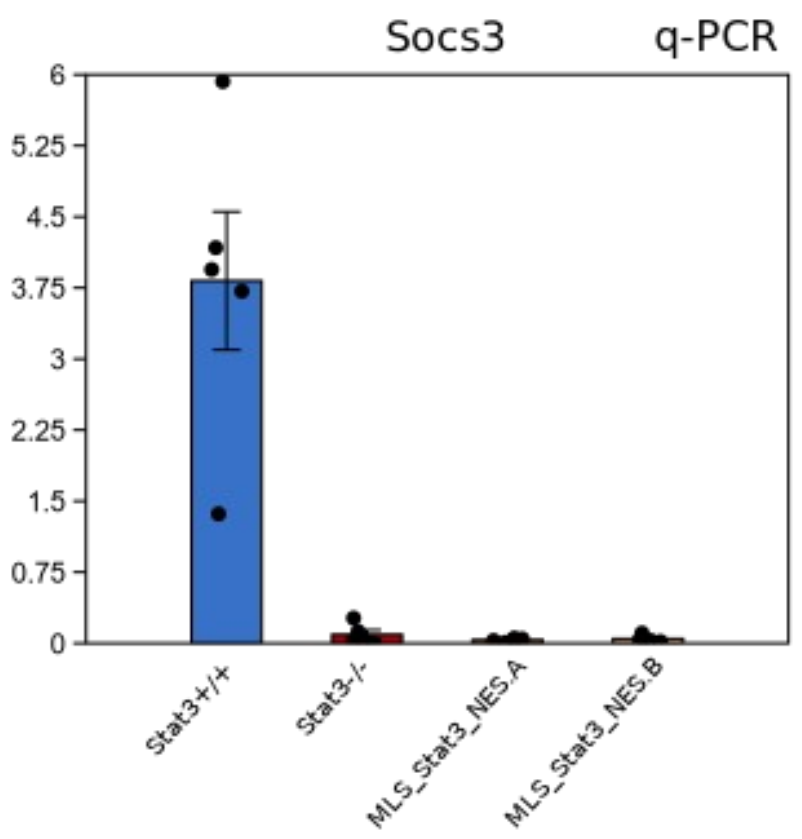

MLS_Stat3_NES.A MLS_Stat3_NES.B
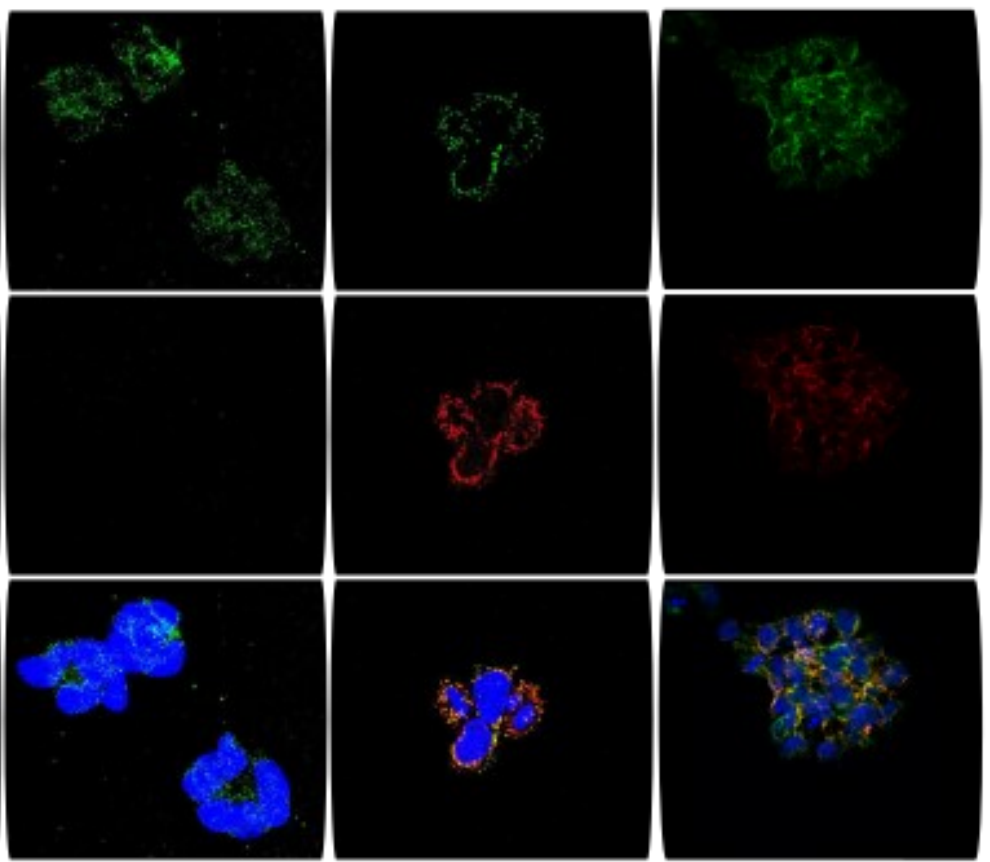
Fig. S1: Validation of the MLS_Stat3_NES construct in murine Embryonic Stem Cells. A: Western blot for total STAT3 on Stat $3^{+/+}$, Stat3 ${ }^{-/-}$and MLS_Stat3_NES cells. Note the shift in molecular weight due to the presence of MLS and NES tags. STAT3 protein level in both MLS_Stat3_NES clones is lower than $S t a t 3^{+/+}$cells. B: qPCR analysis of the Stat3 and its nuclear target gene Socs3. Gene expression analysis of Stat $3^{+/+}$cells, Stat3 ${ }^{-/}$cells, and two MLS_Stat3_NES clones (A/B) cultured in presence of LIF. Note that both clones have the same undetectable level of Socs3 as Stat ${ }^{-1-}$ cells. C: Representative confocal images of Stat3 ${ }^{+/+}$, Stat3 ${ }^{-/-}$and MLS_Stat3_NES cells stained with anti-STAT3 and anti-ATAD3 antibodies. Merge image shows colocalization between STAT3 and the nucleoids marked by ATAD3; DAPI serves as a nuclear counterstain. Scale bar: $20 \mu \mathrm{m}$. 
Fig. S2

Inj mSTAT3 Inj MLS mSTAT3

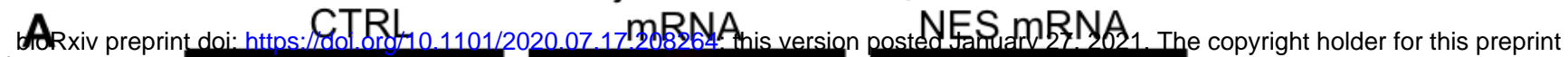
(which was not $C$
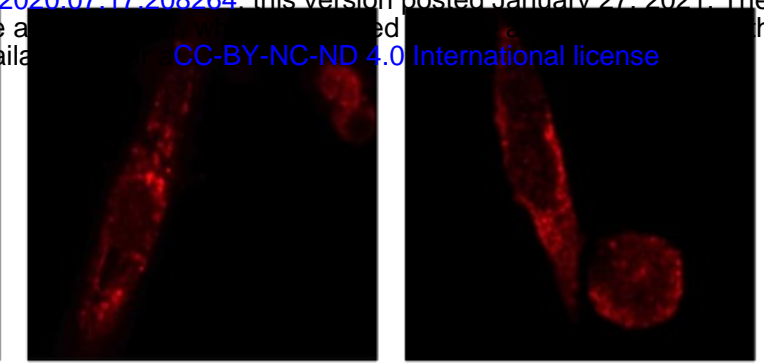

\section{ATAD3}
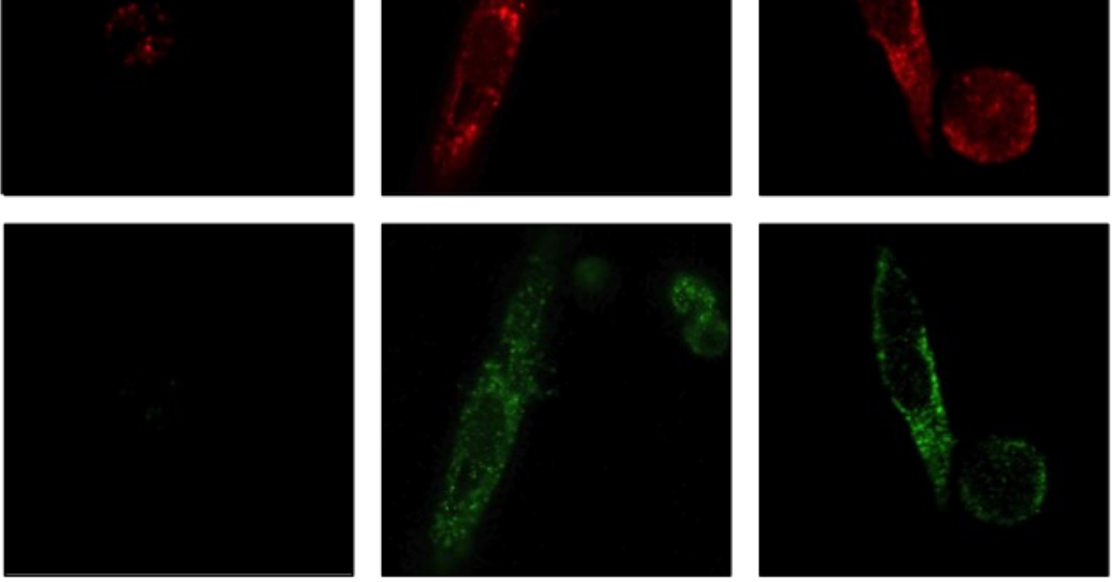

mSTAT3
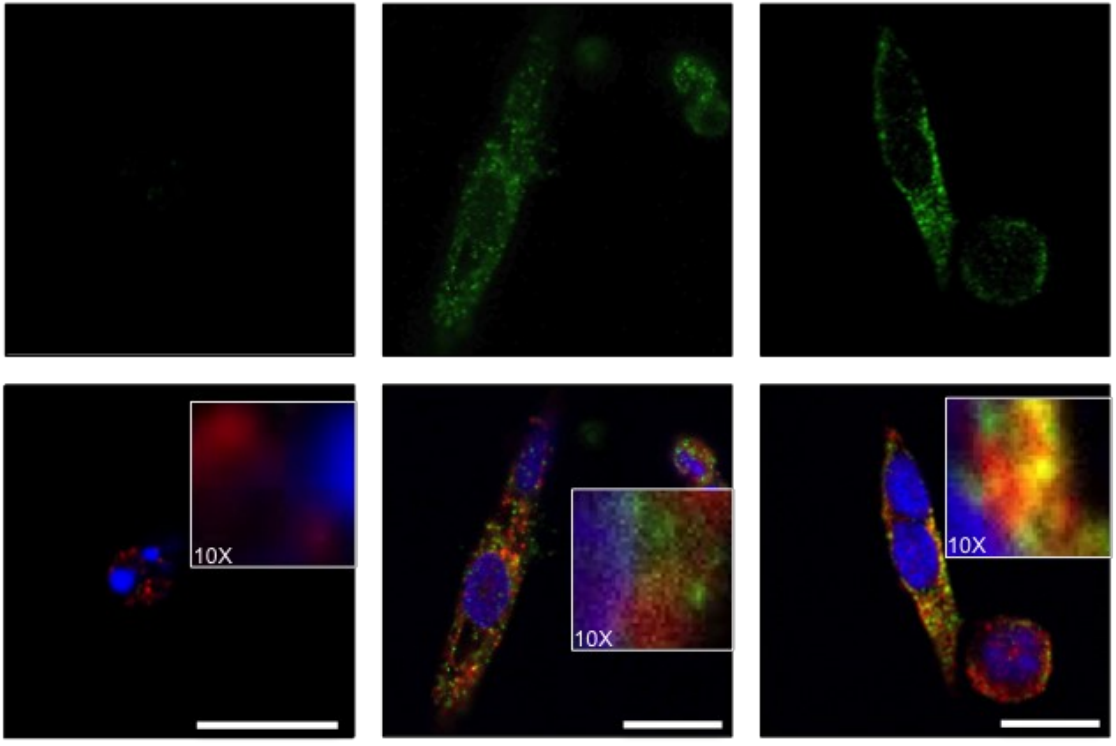

MERGE

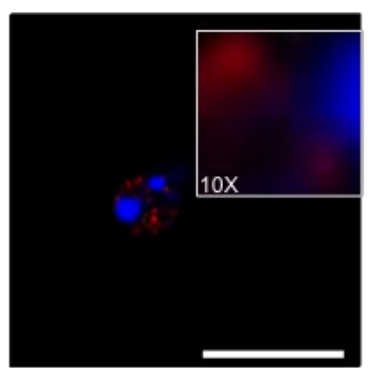

B
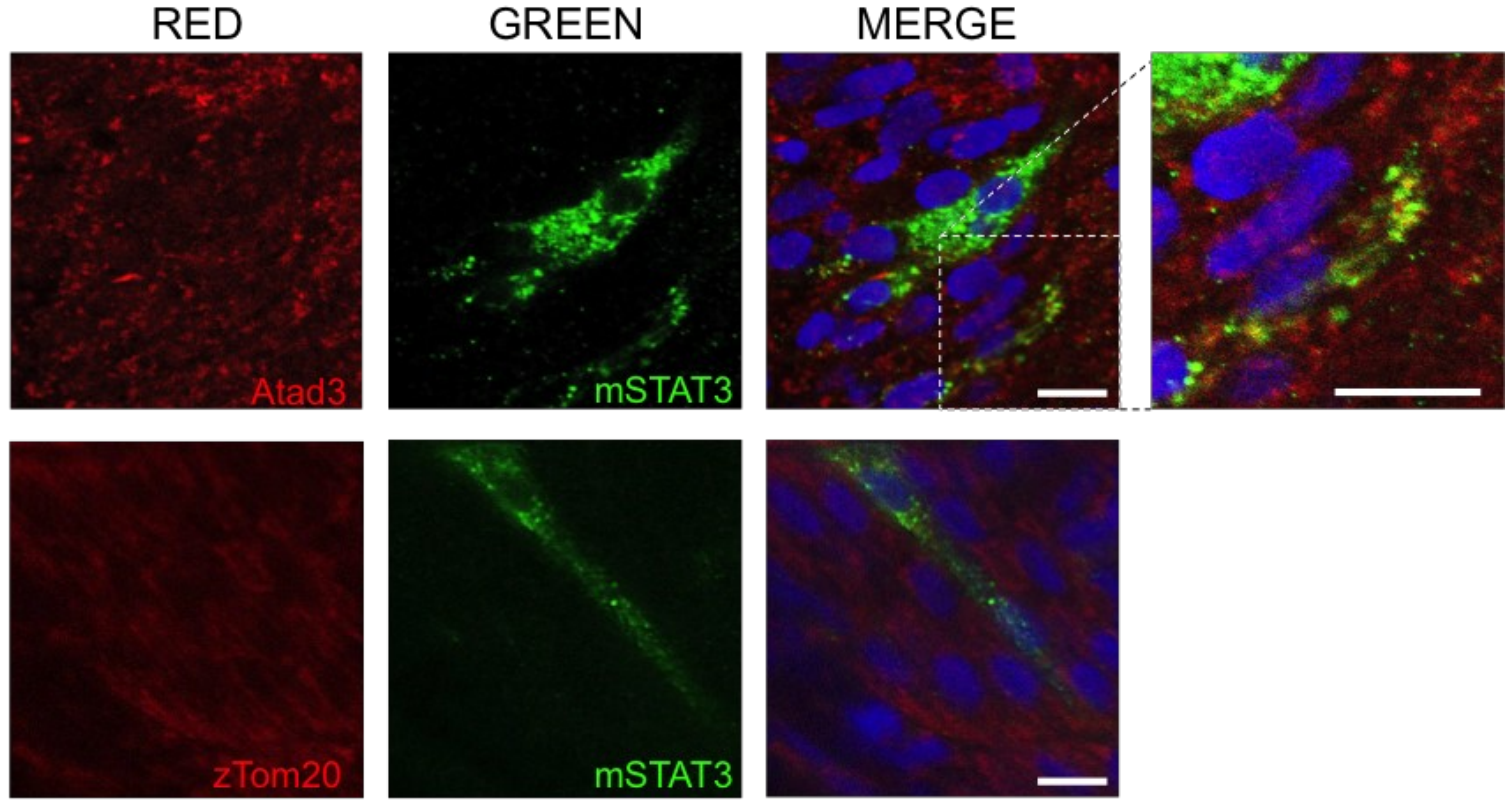
Fig S2: Validation of the injected mRNAs on zebrafish. A: IF on zebrafish cells, dissociated and plated from 24-hpf embryos injected with $m$ Stat3 and MLS_mStat3 mRNA. The antibody reveals the expression of mSTAT3 (green). The mito-targeted STAT3 co-localizes with ATAD3 (red), a marker of mitochondrial nucleoids, confirming the correct subcellular localization of the proteins. Conversely the analysis of cells from embryos injected with $m$ Stat 3 mRNA results in a more diffused staining. Scale bar $=$ 10um. B: Whole mount IF on 24-hpf zebrafish embryos injected with pCS2 + MLS_mSTAT3_NES plasmid. The mosaic expression is driven by a CMV promoter to verify the intracellular localization of the murine protein. mSTAT3 (green) staining confirms the expected mitochondrial localization of the protein 
bioRxiv preprint doi: https://doi.org/10.1101/2020.07.17.208264; this version posted January 27, 2021. The copyright holder for this preprint (which was not certified by peer review) is the author/funder, who has granted bioRxiv a license to display the preprint in perpetuity. It is made available under aCC-BY-NC-ND 4.0 International license.
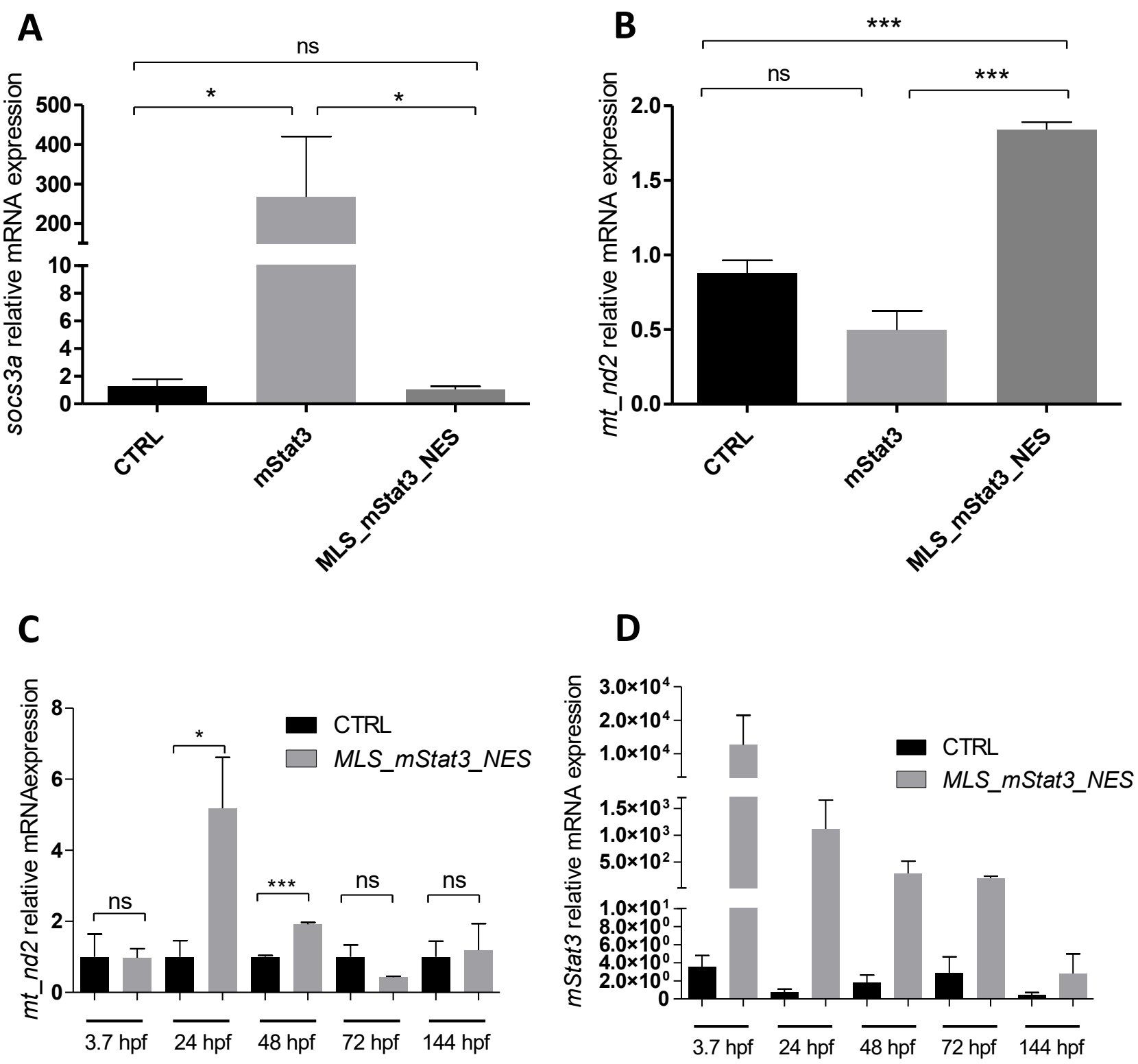

Fig S3: Validation of effects of mStat3 and MLS_Stat3_NES mRNA injected in zebrafish embryos A: qRT-PCR analysis of socs3a mRNA levels in 48-hpf embryos injected with mStat3 and MLS_mStat3_NES. B: qRT-PCR analysis of mt_nd2 mRNA levels in mStat3 and MLS_mStat3_NES 48-hpf injected embryos. C: qRT-PCR analysis of $\mathrm{mt}$ nd2 levels from $3.7 \mathrm{hpf}$ to $6 \mathrm{dpf}$, in larvae injected with mStat3 mRNA. D: qRT-PCR analysis of mStat3 levels from 3.7 hpf to $6 \mathrm{dpf}$, in larvae injected with mStat3 mRNA. Statistical analysis was performed by unpaired t-test on 3 independent biological samples (where $n$ not specified). ${ }^{*} p<0.05$; ${ }^{* \star *} \mathrm{p}<0.001$; error bars $=$ SEM. 
bioRxiv preprint doi: https://doi.org/10.1101/2020.07.17.208264; this version posted January 27, 2021. The copyright holder for this preprint (which was not certified by peer review) is the author/funder, who has granted bioRxiv a license to display the preprint in perpetuity. It is made available under aCC-BY-NC-ND 4.0 International license.

A

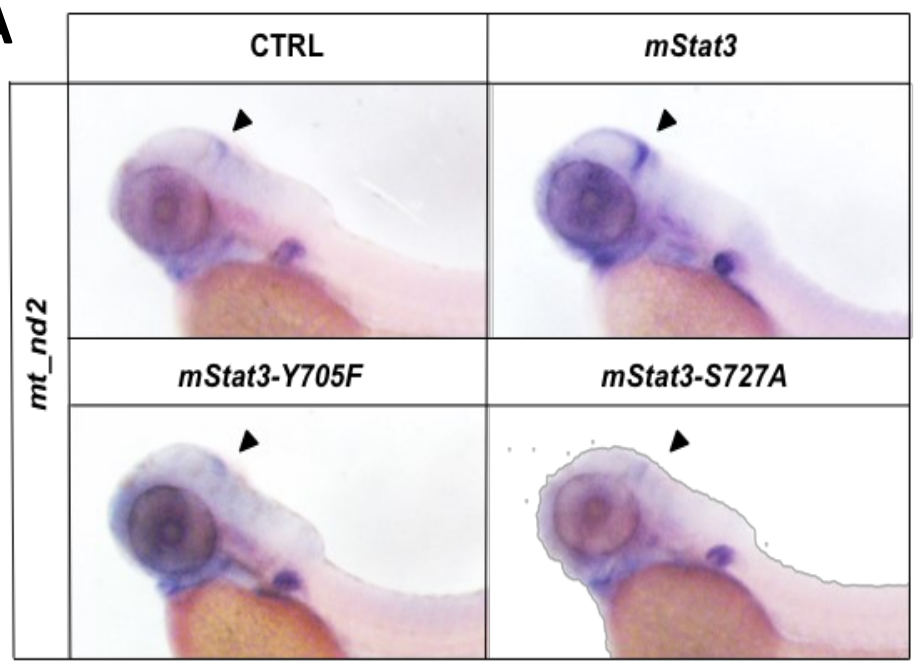

B

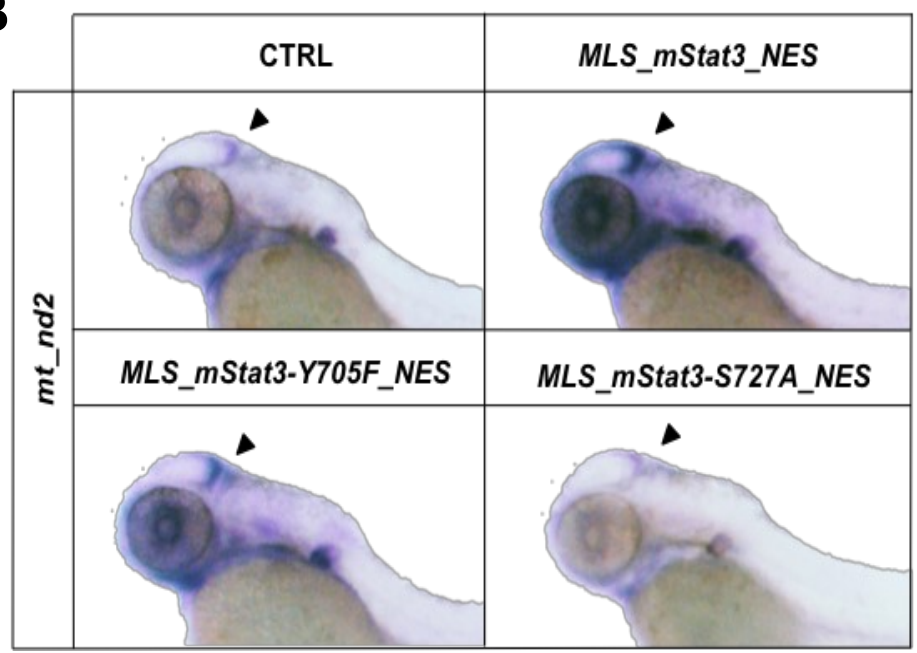

Fig. S4: STAT3-dependent mitochondrial transcription depends on Y705 and S727 phosphorylations. A: WISH with anti-mt_nd2 mRNA probe in 48-hpf uninjected embryos and embryos injected with either mStat3, mStat3-Y705F or mStat3-S727A. B: WISH with antimt_nd2 mRNA probe in 48-hpf uninjected embryos and embryos injected with either MLS_mStat3_NES, MLS_mStat3_NES Y705F or MLS_mStat3_NES S727A. 
bioRxiv preprint doi: https://doi.org/10.1101/2020.07.17.208264; this version posted January 27, 2021. The copyright holder for this preprint (which was not certified by peer review) is the author/funder, who has granted bioRxiv a license to display the preprint in perpetuity. It is made available under aCC-BY-NC-ND 4.0 International license.

A

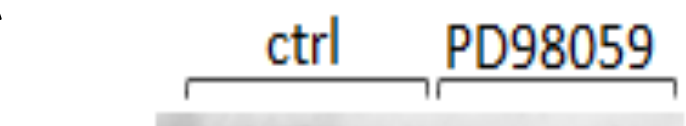

$80 \mathrm{kDa}$ $40 \mathrm{kDa}$
pSTAT3 S727

$\beta$ Actin
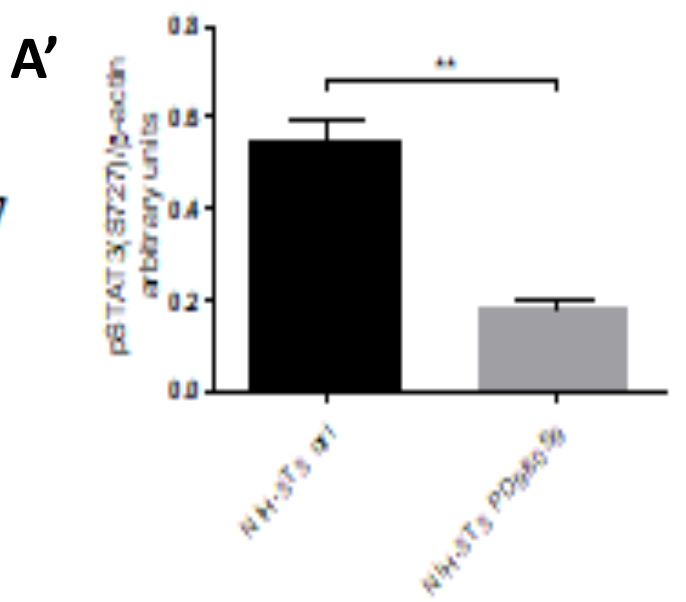

Fig. S5: PD98059 inhibits S727 phosphorylation of STAT3 in NIH-3T3 cells. A-A': western blot analysis of pSTAT3 S727 in NIH-3T3 cells treated for 24 hours with $12.5 \mu$ M PD98059 ( $\beta$-Actin was used as a loading control). Statistical analysis was performed by unpaired t-test on 3 independent biological samples. * $\mathrm{p}<0.05$; error bars=SEM. 
bioRxiv preprint doi: https://doi.org/10.1101/2020.07.17.208264; this version posted January 27, 2021. The copyright holder for this preprint (which was not certified by peer review) is the author/funder, who has granted bioRxiv a license to display the preprint in perpetuity. It is made available under aCC-BY-NC-ND 4.0 International license.

A

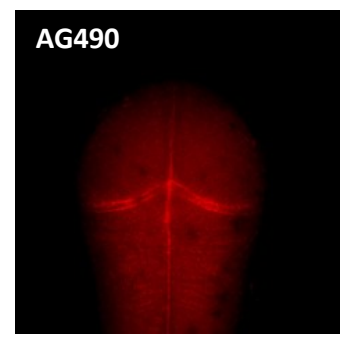

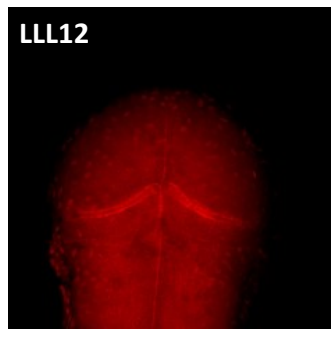

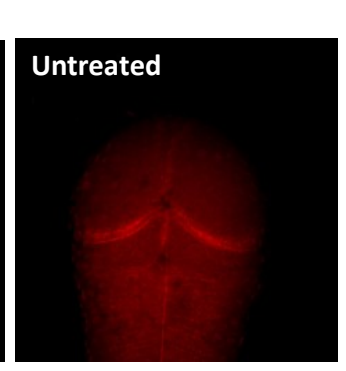

$A^{\prime}$
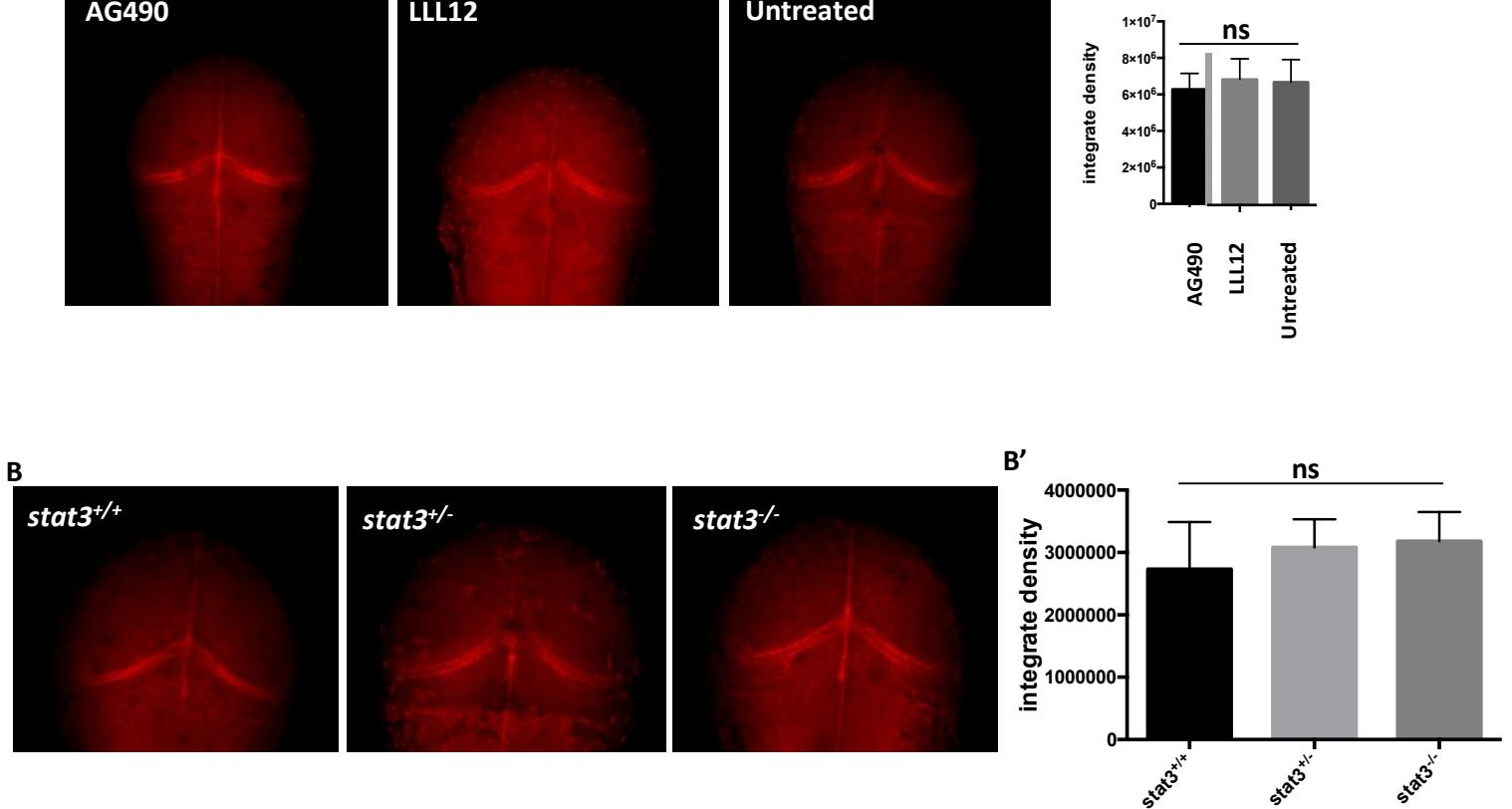

Fig. S6: mt_nd2 mRNA expression is not affected by AG-490 nor in 48-hpf stat3 mutant larvae. A-A': FISH with $\mathrm{mt}$ nd2 probe in the $\mathrm{TeO}$ of 48 -hpf larvae treated for 24 hours with AG490. Fluorescence quantification of $\mathrm{mt} \_n d 2 \mathrm{mRNA}$ levels in the $\mathrm{TeO}(\mathrm{n}=10)$. B: FISH with mt_nd2 probe in the TeO of 48-hpf stat3+/+, stat3+/-, and stat3-/- larvae. B': fluorescence quantification of mt_nd2 mRNA levels in the TeO. Statistical analysis was performed by unpaired t-test on 3 independent biological samples. ns = not significant; error bars=SEM. 
bioRxiv preprint doi: https://doi.org/10.1101/2020.07.17.208264; this version posted January 27, 2021. The copyright holder for this preprint (which was not certified by peer review) is the author/funder, who has granted bioRxiv a license to display the preprint in perpetuity. It is made

A

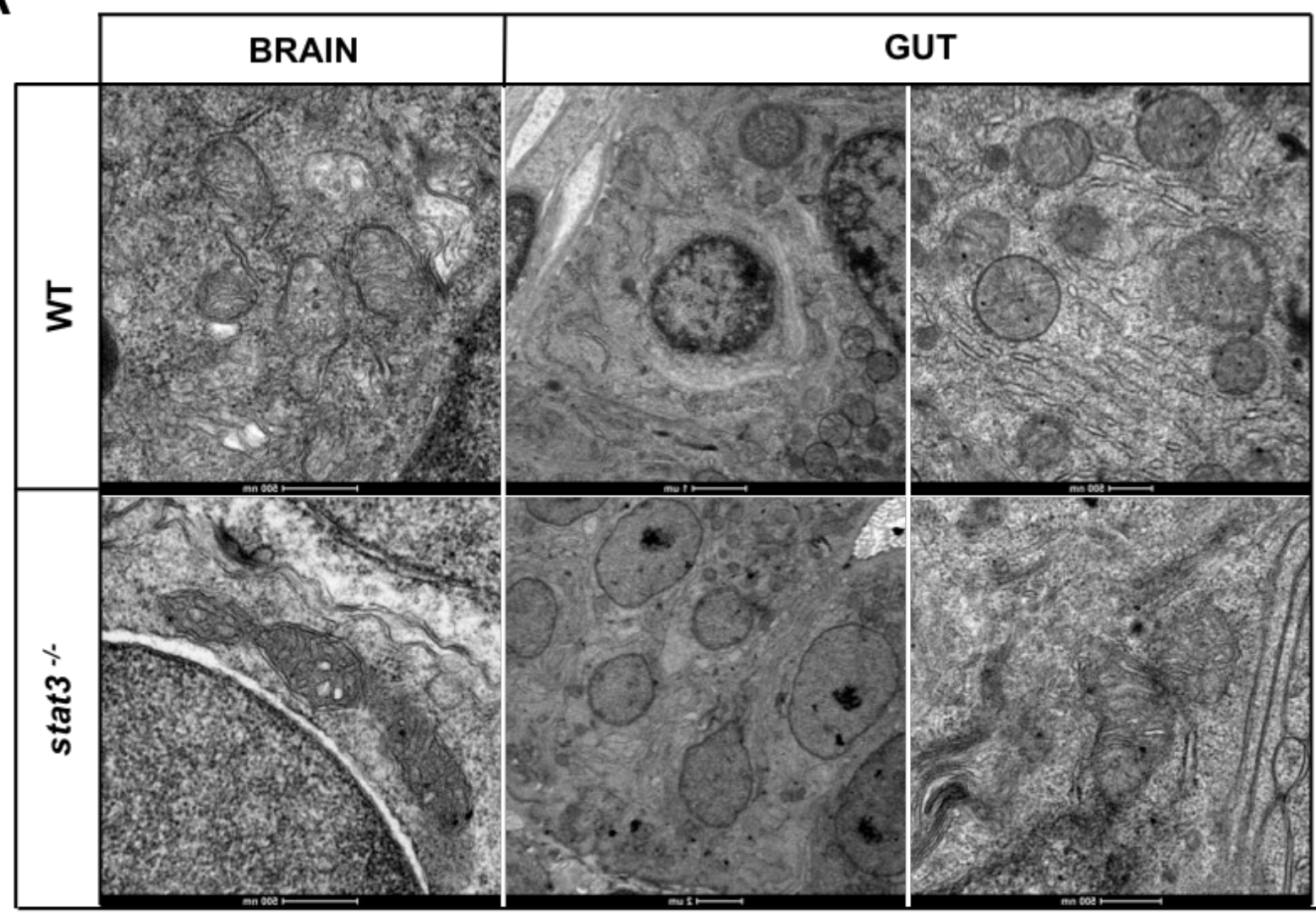

B

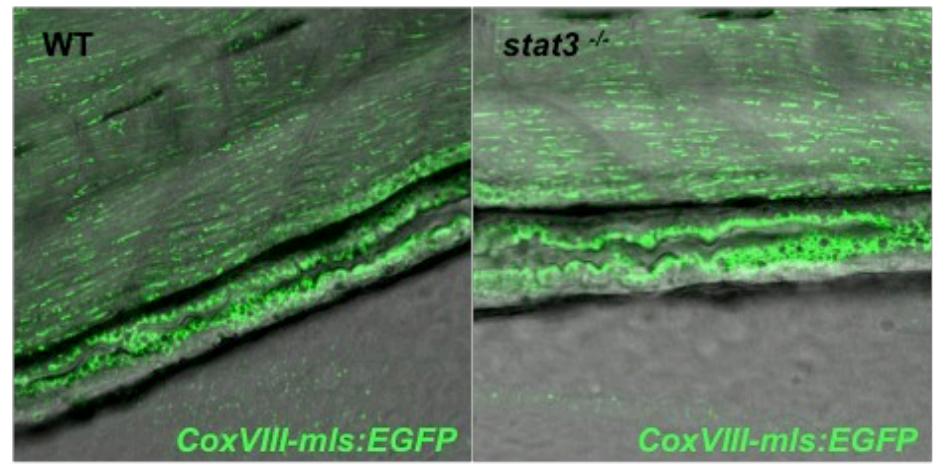

C

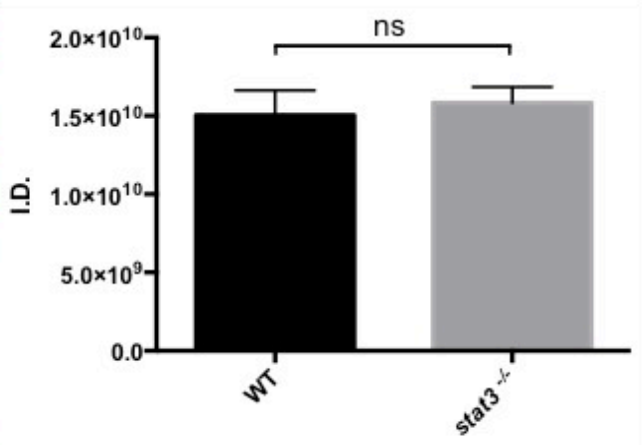

Fig. S7: Stat3 depletion does not affect mitochondria morphology and biogenesis in the brain and intestine of stat3-/- larvae. A: TEM analysis of mitochondrial morphology in intestine and brain of 6-dpf stat3-/- mutants and WT siblings. B: EGFP expression in the intestine of 6-dpf stat3-/-/Tg(CoxVIII-mls:EGFP) and WT/Tg(CoxVIII-mls:EGFP) siblings $(n=6)$. C: Fluorescence quantification of EGFP expression in the intestine of 6-dpf stat3-/-/ $\mathrm{Tg}$ (CoxVIII-mls:EGFP) and WT/Tg(CoxVIII-mls:EGFP) siblings ( $p$-value=0.,6878). Statistical analysis was performed by unpaired t-test on indicated number of samples; ns = not significant; error bars=SEM. 
bioRxiv preprint doi: https://doi.org/10.1101/2020.07.17.208264; this version posted January 27, 2021. The copyright holder for this preprint (which was not certified by peer review) is the author/funder, who has granted bioRxiv a license to display the preprint in perpetuity. It is made available under aCC-BY-NC-ND 4.0 International license.

\begin{tabular}{|c|c|c|}
\hline \multicolumn{3}{|c|}{ sgRNA } \\
\hline Exon & Sequence & Reference \\
\hline 14 & GGUCGAUCUUAAGUCCUUGG & Peron et al. (2020) \\
\hline 22 & AGUGAGCUGCUUGGGAA & This paper \\
\hline 23 & AUGAGAGAGUCGAGCGUGCG & This paper \\
\hline \multicolumn{3}{|c|}{ Genotyping } \\
\hline Primer & Primer sequence & Reference \\
\hline stat3 ex14 fw & GGCCTCTCTGATAGTGACCG & Peron et al. (2020) \\
\hline stat3 ex14 rv & AGTTGTGCTTAGACGCGATC & Peron et al. (2020) \\
\hline stat3 ex22 fw & GTGTGTGTGTTAGGCAGGCT & This paper \\
\hline stat3 ex22 rv & AGCTCCCTAATGCCTACCCA & This paper \\
\hline stat3 ex22 fw & TGCAGGACTAACTCTGGCAA & This paper \\
\hline stat3 ex23 rv & GCTTCGTTGTGCATGAGAGA & This paper \\
\hline$n r 3 c 1 f w$ & ACCACTTCAAGCGGACAGAG & Facchinello et al. (2017) \\
\hline$n r 3 c 1 r v$ & CCGGCTTCTGATCTTTCTGC & Facchinello et al. (2017) \\
\hline
\end{tabular}

\begin{tabular}{|c|c|}
\hline Primer name & Primer sequence \\
\hline MLS_STAT3_NES_Y705F $f w$ & GCTGCCCCGTTCCTGAAGACC \\
\hline MLS_STAT3_NES_Y7705F rv & ACTACCTGGGTCGGCTTC \\
\hline MLS_STAT3_NES_S727A fw & CCTGCCGATGGCCCCCCGCAC \\
\hline MLS_STAT3_NES_S727A rv & TCAATGGTATTGCTGCAGGTCGTTGGTGTC \\
\hline MLS_STAT3_NES_ADNAbd $f w$ & GGCGATCTCCAACATCTGTCAGATGC \\
\hline MLS_STAT3_NES_ADNAbd rv & GCGGCTGGCAAGGAGTGGGTCTC \\
\hline
\end{tabular}


Table 2

bioRxiv preprint doi: https://doi.org/10.1101/2020.07.17.208264; this version posted January 27, 2021. The copyright holder for this preprint (which was not certified by peer review) is the author/funder, who has granted bioRxiv a license to display the preprint in perpetuity. It is made available under aCC-BY-NC-ND 4.0 International license.

\begin{tabular}{|l|l|l|}
\hline Gene & Forward primer sequence & Reverse primer sequence \\
\hline zmt_nd2 & GCAGTAGAAGCCACCACAAA & GCTAGACCGATTTTGAGAGCC \\
\hline zgapdh & GTGGAGTCTACTGGTGTCTTC & GTGCAGGAGGCATTGCTTACA \\
\hline zpcna & CCTTGGCACTGGTCTTTGAA & GGCACACGAGATCATGACAG \\
\hline zsocs3a & GGAAGACAAGAGCCGAGACT & GCGATACACACCAAACCCTG \\
\hline mSocs3 & ATTTCGCTTCGGGACTAGC & AACTTGCTGTGGGTGACCAT \\
\hline mStat3 & TGTTGGAGCAGCATCTTCAG & GAGGTTCTCCACCACCTTCA \\
\hline mbactin & CTAAGGCCAACCGTGAAAAG & ACCAGAGGGCATACAGGGACA \\
\hline
\end{tabular}

